\title{
The Climatology of the Atmospheric Boundary Layer in Contemporary Global Climate Models 0
}

\author{
RICHARD DAVY \\ Nansen Environmental and Remote Sensing Center, Bergen, Norway
}

(Manuscript received 26 July 2017, in final form 28 August 2018)

\begin{abstract}
Here, we present the climatology of the planetary boundary layer depth in 18 contemporary general circulation models (GCMs) in simulations of the late-twentieth-century climate that were part of phase 5 of the Coupled Model Intercomparison Project (CMIP5). We used a bulk Richardson methodology to establish the boundary layer depth from the 6-hourly synoptic-snapshot data available in the CMIP5 archives. We present an ensemble analysis of the climatological mean, diurnal cycle, and seasonal cycle of the boundary layer depth in these models and compare it to the climatologies from the ECMWF ERA-Interim reanalysis. Overall, we find that the CMIP5 models do a reasonably good job of reproducing the distribution of mean boundary layer depth, although the geographical patterns vary considerably between models. However, the models are biased toward weaker diurnal and seasonal cycles in the boundary layer depth and generally produce much deeper boundary layers at night and during the winter than are found in the reanalysis. These biases are likely to reduce the ability of these models to accurately represent other properties of the diurnal and seasonal cycles, and the sensitivity of these cycles to climate change.
\end{abstract}

\section{Introduction}

The planetary boundary layer (PBL) depth is a very important quantity within the climate and climate models. The PBL governs the turbulent exchange of heat, moisture, carbon, momentum, and aerosols between the surface and the atmosphere. The depth of the PBL is also a controlling factor in determining the nearsurface concentration of pollutants (Arya 1999; Akimoto 2003; Quan et al. 2014) and heat (Oke 1976, 1995; Davy and Esau 2016). It has been shown that the parameterization of turbulence within different PBL schemes can strongly affect the surface climate in numerical weather prediction and climate models, as well as the sensitivity of the model climate to changes in external forcing (Garratt 1993; Holtslag and Boville 1993; Esau and Zilitinkevich 2010; Davy and Esau 2016). This has motivated the creation of several model intercomparison programs that have sought to identify and quantify the

\footnotetext{
Supplemental information related to this paper is available at the Journals Online website: https://doi.org/10.1175/JCLI-D-170498.s1.
}

Corresponding author: Richard Davy, richard.davy@nersc.no limitations of existing PBL schemes, most notably the GEWEX Atmospheric Boundary Layer Studies (GABLS; Holtslag 2006). There have been several intercomparison studies within the GABLS framework, ranging from highly idealized scenarios with prescribed boundary conditions to more complex scenarios including surface coupling with comparisons to field observations (Beare et al. 2006; Svensson et al. 2011; Bosveld et al. 2014a). These single-column model (SCM) studies have helped identify the limitations of existing PBL schemes in representing the atmospheric response to surface cooling, the diurnal cycle, and atmospheric-land surface coupling (Svensson and Holtslag 2008; Bosveld et al. 2014b).

One of the conclusions from the later GABLS experiments was that the interaction with land surface schemes has a strong modulating influence on the spread of the different PBL schemes when compared to their performance using fixed surface boundary conditions. This has also been demonstrated using perturbed-physics experiments on the PBL scheme of the European Centre for Medium-Range Weather Forecasts (ECMWF) forecast model. Holtslag et al. (2013) showed that the same change in the PBL scheme for stably stratified boundary layers in two versions of the ECMWF forecast model led to two very different changes in the wintertime 
climatology of the surface air temperature (SAT). The authors attributed this to the coupling of the PBL scheme with the soil hydrology and snow parameterization schemes, which had been altered between the two different versions of the ECMWF model.

The PBL depth is not just affected by internal parameters and interaction with the land surface but by the numerous other parameterization schemes that affect the near-surface radiation balance and/or the largescale atmospheric stability. Experiments such as the perturbed-physics experiment with the ECMWF model have demonstrated that the interaction between different parameterization schemes can be more important in determining the changes to the surface climate than are changes to an individual parameterization scheme. This is one reason for an assessment of the climatology of the PBL depth in global climate models. Each global climate model is composed of a unique combination of schemes describing the physics of the Earth system. Each model has its own internal climate variability that is the net result of the interaction of all these parameterization schemes. An assessment of the climatology of the PBL depth in these models, and how they compare to observationally constrained climatologies, allows us to determine if these models are reproducing the observed range and frequency of PBL depths.

Because of its important role in the climate system, there have been numerous studies that have sought to determine the climatology of the PBL depth from observations, reanalyses, and climate models (Liu and Liang 2010; Seidel et al. 2012; Von Engeln and Teixeira 2013; Wang and Wang 2016). There are several challenges to creating a climatology of the PBL depth. For example, there are the limitations due to sampling frequency. The PBL depth has a strong diurnal cycle over land and can vary by several kilometers in desert regions, so it is necessary to have a relatively high sampling frequency to accurately capture the diurnal cycle and avoid biases in the resultant climatologies. This is a common problem for observational climatologies such as those using radiosonde observations because these are typically only taken a couple of times per day (Seidel et al. 2010), and they miss the important diurnal transitions in the PBL (Angevine 2008). Therefore, robust observational climatologies are limited to analysis of the more detailed studies from field campaigns (Liu and Liang 2010), although radiosonde observations have been demonstrated to be useful for assessing longterm trends in PBL depth (Wang and Wang 2016). While this is a common problem for observational climatologies, this can also be a problem in the assessment of archived model data as the three-dimensional data needed for quantification of the PBL depth is often only recorded at 6-hourly resolution, as is the case for the CMIP5 archives.

Another challenge faced in constructing a climatology of the PBL depth is that there are several methods for estimating the depth of the PBL, and they can all lead to very different results regardless of whether they are applied to observations, reanalyses, or climate models (Seidel et al. 2010; Von Engeln and Teixeira 2013; McGrath-Spangler and Molod 2014; Svensson and Lindvall 2015). Many of these studies have sought to quantify the uncertainty in the PBL depth that stems from the choice of method and have shown that this can vary considerably between climate classes as well as within the diurnal and seasonal cycles. As yet, there is no consensus on the best method for determining PBL depth, although it has been shown that the bulk Richardson method is the most consistent method when comparing models and observations across a range of conditions and has, therefore, been recommended for use in application to global climate models (Seidel et al. 2010; McGrath-Spangler and Molod 2014). This method can capture the relatively shallow layers found under stable stratification, which is typical of nighttimes and the high latitudes. It also gives the best match to observation-based estimates of the PBL depth derived using radiosonde data.

For the reasons listed above, and due to the limitations on the availability of the data, we chose to calculate the PBL depth in the CMIP5 GCMs using a bulk Richardson methodology. We employed this methodology to calculate the boundary layer depth at the 6-hourly resolution for the last 30 years, 1976-2005, of the CMIP5 "historical" simulations for the 18 global climate models for which data were available on the model-level grid, rather than the pressurelevel grid. We then created climatologies of the diurnal and seasonal cycles of the PBL depth in these models and performed an ensemble analysis (mean and spread) of the 18 GCMs under consideration. The major limitation of using the bulk Richardson methodology is its application to overocean locations. Here, the method is more likely to retrieve the marine cloud-base height, which is not necessarily representative of the true mixed-layer depth (Janssen and Bidlot 2003). For this reason we focus our discussion of the PBL depth climatology on the overland results.

For the first time, we have quantified the PBL depth in the full range of CMIP5 models for which sufficient data are available. In this manuscript we present an ensemble analysis of the resultant climatologies in the PBL depth. In section 2 we present the data and methodology behind our calculations of the climatologies; in section 3 we show the climatologies from the individual models along with the ensemble mean and spread; in section 4 we present the comparison of the ensemble-mean 
TABLE 1. List of models used in the analysis along with the center that produced them, whether or not they have surface wind speed data available, the vertical and horizontal resolution used in the simulations, and the original reference where the model was first presented. Expansions of acronyms are available online at http://www.ametsoc.org/PubsAcronymList.

\begin{tabular}{|c|c|c|c|c|c|}
\hline Model name & Center & $\begin{array}{l}\text { Surface } \\
\text { wind }\end{array}$ & $\begin{array}{l}\text { Vertical } \\
\text { resolution }\end{array}$ & $\begin{array}{l}\text { Horizontal } \\
\text { resolution }\end{array}$ & Reference \\
\hline ACCESS1.0 & CSIRO/BOM & Yes & L38 & $192 \times 145$ & Bi et al. (2013) \\
\hline ACCESS1.3 & CSIRO/BOM & Yes & L38 & $192 \times 145$ & Bi et al. (2013) \\
\hline BCC_CSM1 & $\mathrm{BCC}$ & Yes & L26 & $128 \times 64$ & Wu et al. (2014) \\
\hline BCC_CSM1M & $\mathrm{BCC}$ & Yes & L26 & $320 \times 160$ & Wu et al. (2014) \\
\hline CCSM4 & NCAR & No & L26 & $288 \times 192$ & Meehl et al. (2012) \\
\hline CNRM-CM5 & CNRM & Yes & L31 & $256 \times 128$ & Voldoire et al. (2013) \\
\hline FGOALS-g2 & $\begin{array}{l}\text { LASG/Center for Earth System } \\
\text { Science (CESS) }\end{array}$ & No & L26 & $128 \times 60$ & Li et al. (2013) \\
\hline GFDL CM3 & GFDL & Yes & L48 & $144 \times 90$ & Griffies et al. (2011) \\
\hline GFDL-ESM2G & GFDL & Yes & L24 & $144 \times 90$ & Dunne et al. (2012) \\
\hline GFDL-ESM2M & GFDL & Yes & L24 & $144 \times 90$ & Dunne et al. (2012) \\
\hline HadGEM2-ES & Met Office Hadley Centre (MOHC) & Yes & L38 & $192 \times 145$ & Jones et al. (2011) \\
\hline IPSL-CM5A-LR & IPSL & Yes & L39 & $96 \times 96$ & Dufresne et al. (2013) \\
\hline IPSL-CM5A-MR & IPSL & Yes & L39 & $144 \times 142$ & Dufresne et al. (2013) \\
\hline MIROC5 & $\begin{array}{l}\text { AORI/National Institute for } \\
\text { Environmental Studies (NIES)/ } \\
\text { JAMSTEC }\end{array}$ & Yes & L40 & $256 \times 128$ & Watanabe et al. (2010) \\
\hline MIROC-ESM & JAMSTEC/NIES & Yes & L80 & $128 \times 64$ & Watanabe et al. (2011) \\
\hline MIROC-ESM-CHEM & JAMSTEC/NIES & Yes & L80 & $128 \times 64$ & Watanabe et al. (2011) \\
\hline MRI-CGCM3 & MRI & Yes & L48 & $320 \times 160$ & Yukimoto et al. (2012) \\
\hline NorESM1-M & Norwegian Climate Centre (NCC) & No & L26 & $144 \times 96$ & Bentsen et al. (2013) \\
\hline
\end{tabular}

climatologies with those derived from a reanalysis product, ERA-Interim; and finally in section 5 we discuss some of the consistent features of the PBL climatology in the climate models and potential implications for other aspects of the climate system in these models.

\section{Method}

The 6-hourly three-dimensional and 3-hourly nearsurface fields for air temperature, humidity, surface sensible heat flux (3-hourly means), and wind speed in the window 1976-2005 of the historical scenario were acquired from the CMIP5 results archived by the British Atmospheric Data Center (http://browse.ceda.ac.uk/browse/badc/ cmip5/). To ensure that we had a sufficiently high nearsurface resolution to reasonably capture the shallower boundary layers with depths of tens or hundreds of meters, we selected only those models for which there was model-level data available for the atmosphere. There were a total of 18 models for which model-level data were available, but only 15 of these models also had nearsurface wind speed data. The details of each model used in the study are listed in Table 1 . For each model we selected only one simulation from the archives, designated r1i1p1, which is the first realization, initialization, and set of model physics chosen by the modeling group.

The model vertical and horizontal resolutions are highly varied with horizontal grid resolutions ranging from $96 \times 96$ for IPSL-CM5A-LR to $320 \times 160$ for the
BCC_CSM1.1(m) and MRI-CGCM3 models and vertical resolutions ranging from 24 to 80 levels (Table 1). It is difficult to predict the impact that these different model resolutions may have had on the climatologies calculated here because model resolution affects different processes in different ways. It has been demonstrated in single-column models that improving the vertical resolution of the model improves the representation of the boundary layer in comparison with large-eddy simulations (Cuxart et al. 2006). But globally the climatology of the boundary layer is affected by many external processes operating on a range of spatial scales. We do know that minimum resolution requirements exist to capture certain processes important in the global climate system (Shaffrey et al. 2009; Demory et al. 2014; Birch et al. 2015) and that while improving model resolution does not guarantee significant improvements (Johnson et al. 2016), it generally reduces model biases (Hertwig et al. 2015; Prodhomme et al. 2016; de Souza Custodio et al. 2017). So one might expect that models with a higher resolution will generally do a better job in representing the climatology of the PBL depth. However, because of the dependencies on both local and large-scale forcings, and the degree to which they differ between models, we cannot make any such simple extrapolations about the effects of model resolution in this kind of multimodel ensemble. We did find that the intermodel differences in vertical resolution did correlate strongly with the differences in diurnal and 


\section{Ensemble mean}
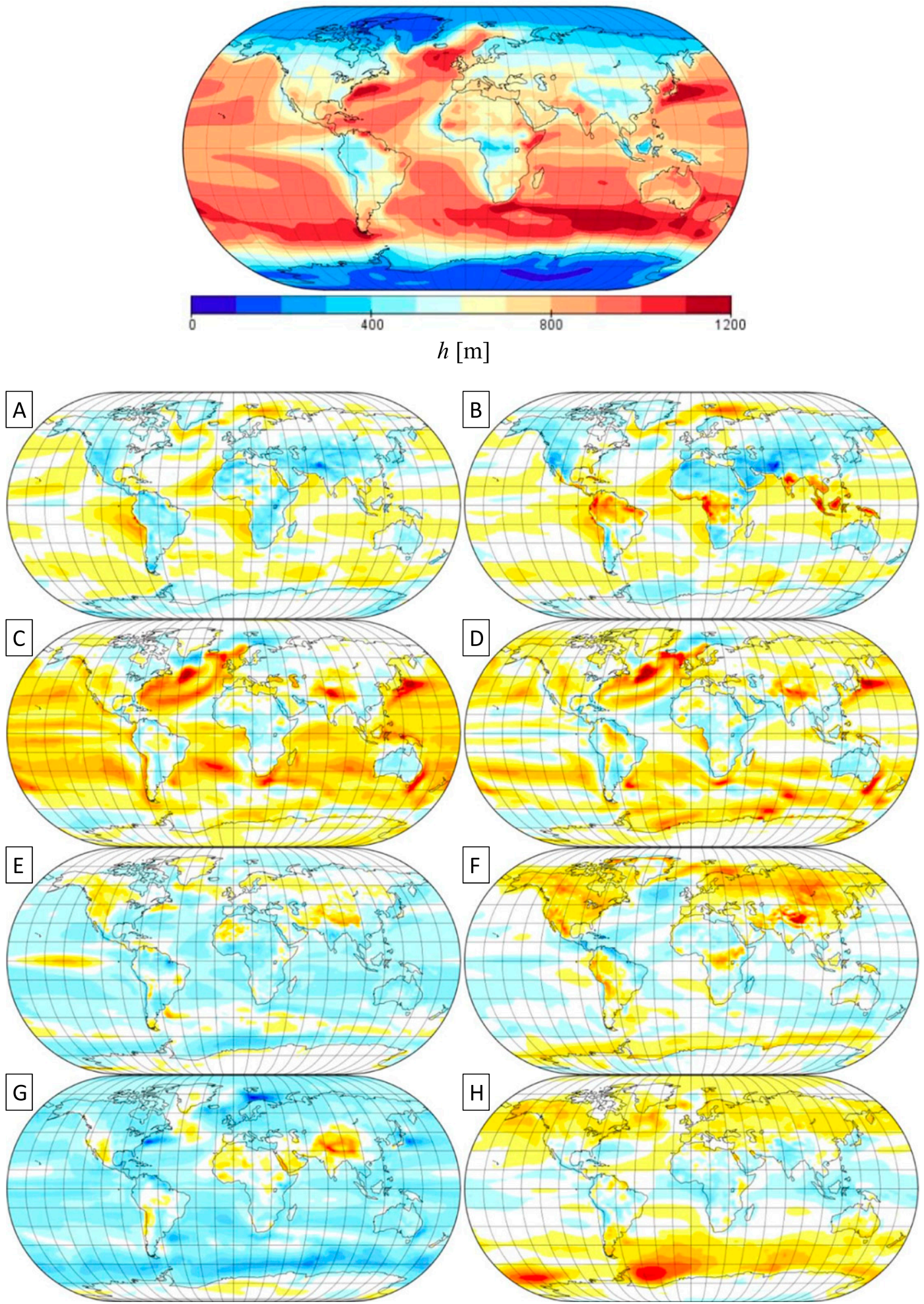

FIG. 1. The climatological-mean boundary layer depth $h(\mathrm{~m})$ from the ensemble mean and the anomalies with respect to the ensemble mean for each of the models from which the ensemble was comprised. 


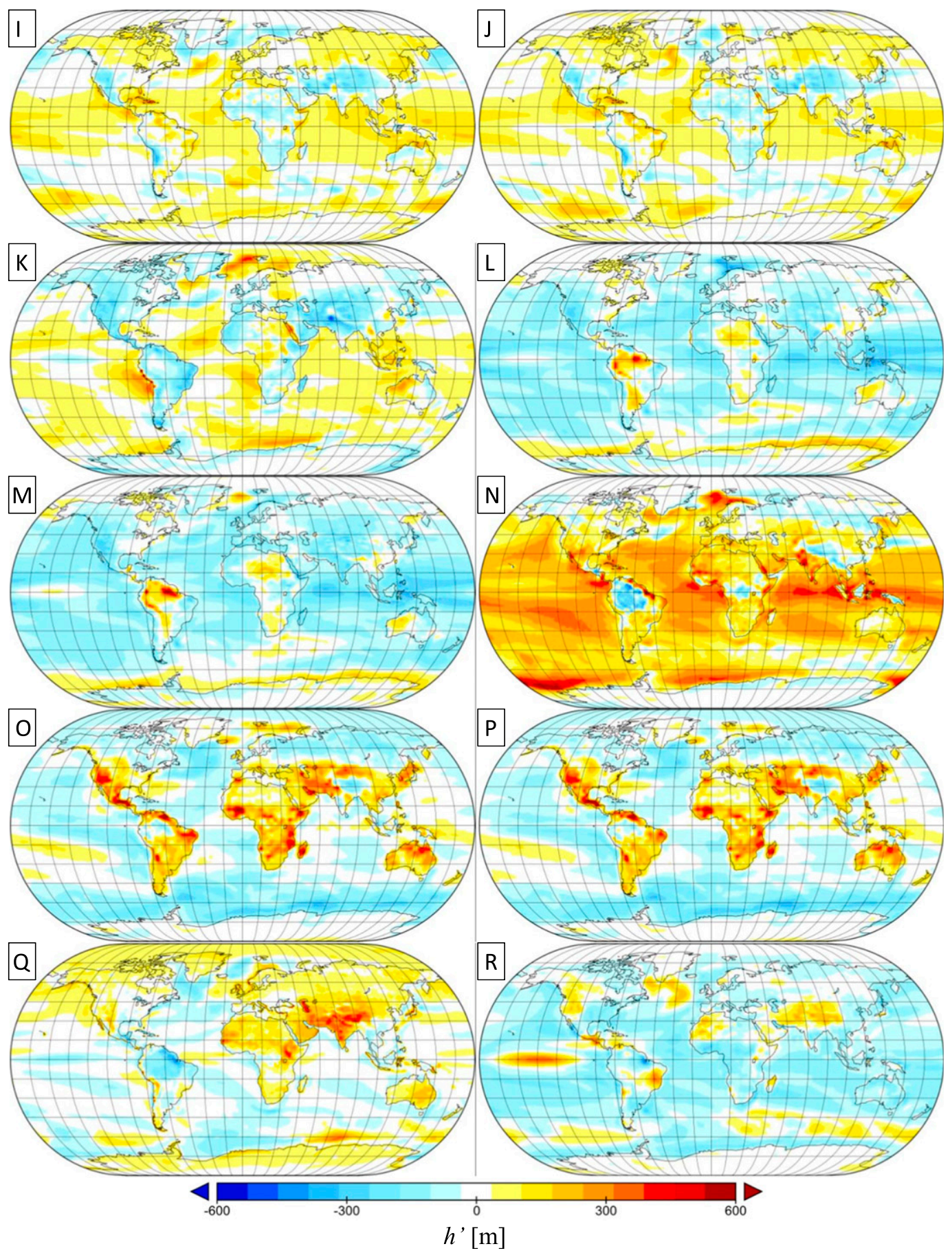

FIG. 1. (Continued)

seasonal minima in PBL depths (see the results below), but there was no such relationship for the climatological means. Similar tests on the dependency of horizontal resolution in the models on the resultant PBL climatologies found no significant relationships.

We have compared the intermodel spread in each climatological measure of the PBL depth (the diurnal cycle, seasonal cycle, and annual mean) against the intermodel spread in several of the factors expected to affect the PBL climatology: the vertical and horizontal resolution, the surface sensible heat flux, and the nearsurface wind speed. While there are many other factors we can anticipate having an effect on the PBL climatology, we were strongly constrained by the availability of subdiurnal 

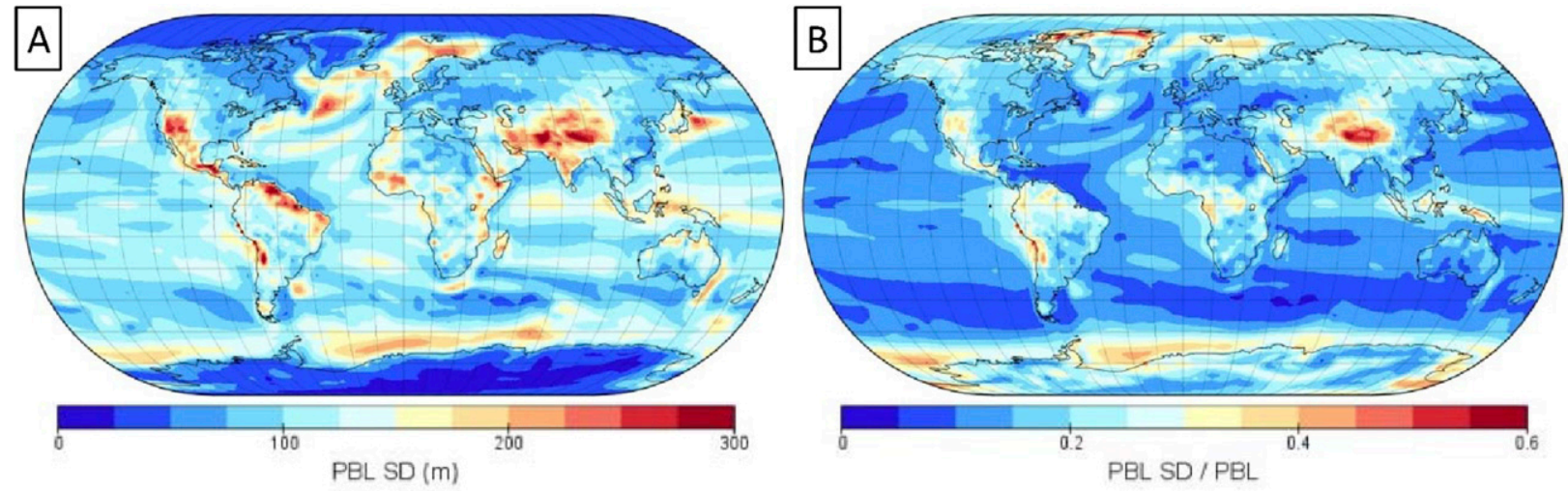

FIG. 2. (a) The standard deviation of the climatological-mean boundary layer depth ( $\mathrm{m}$ ) in the ensemble and (b) the ensemble standard deviation normalized to the ensemble-mean boundary layer depth.

data in the CMIP5 archives. Since these predictors are expected to be related to each other, we used a multiple linear regression to attempt to isolate the effects of each factor (see the online supplemental material). However, since this did not reveal strong relationships either in the grid-point-wise or the area-averaged averaged analysis, we have chosen not to include these results in the main manuscript.

In some models the model-level profiles are available on height levels, but in most they are given on sigma levels. Where sigma levels were used we calculated the thickness of each layer using the hypsometric equation and combined the layer thicknesses to obtain the height of each level. The PBL depth was calculated using a bulk Richardson methodology. This method was chosen because studies have demonstrated that it is the most reliable method to cover a wide range of conditions, which is necessary when creating a global climatology, and it provides the best match to PBL depths derived from radiosonde observations (Seidel et al. 2010; Liu and Liang 2010; McGrath-Spangler and Molod 2014; Lee and De Wekker 2016; Lee and Pal 2017). In this method the PBL depth is defined to be the height at which the bulk Richardson number first exceeds some critical value, which we took to be 0.25 based upon observational evidence of the threshold for Kolmogorov turbulence (Grachev et al. 2013). We tested the sensitivity of the PBL depth to this critical value and found variations in climatological-mean PBL depths in individual models of less than $3 \%$ in response to $20 \%$ variations in the critical value from 0.2 to 0.3 , which is the range of likely values for the critical Richardson number from analysis of observations (Cheng et al. 2002; Zilitinkevich and Esau 2007). Two different methods for calculating the bulk Richardson number were investigated: either neglecting or accounting for surface wind speed in the calculations. However, due to the high degree of similarity in the results (there was a less than $2 \%$ change in the climatological-mean PBL depth within individual models), only the former is presented here.

The water vapor mixing ratio was defined from the humidity: $M=q /(1-q)$. The potential temperature $\theta(\mathrm{K})$ was calculated from the temperature $T(\mathrm{~K})$, sigma level $\sigma$, and water vapor mixing ratio using $\theta=T(1 / \sigma)^{k}$, where $k$ is the Poisson constant taken as $k=0.285(1-0.24 M)$. The virtual potential temperature $\theta_{v}(\mathrm{~K})$ was then calculated from the profiles of potential temperature $\theta$ and the mixing ratio, whereby $\theta_{v}=\theta(1+0.61 M)$. The bulk Richardson number was calculated at every model level by taking the difference between each given model level and the near-surface values:

$$
R_{B i}=\frac{g}{\theta_{v s}} \frac{\left(\theta_{v i}-\theta_{v s}\right) z_{i}}{\left(U_{i}-U_{s}\right)^{2}+\left(V_{i}-V_{s}\right)^{2}}
$$

where $g$ is the acceleration due to gravity $\left(=9.8 \mathrm{~m} \mathrm{~s}^{-2}\right)$; $U$ and $V$ are the components of the wind speed $\left(\mathrm{m} \mathrm{s}^{-1}\right)$, respectively; and $z$ is the height $(\mathrm{m})$. The subscript $i$ denotes the model level, and the subscript $s$ denotes the near-surface value, taken at a height of $2 \mathrm{~m}$ above the ground. We then scan upward to find the first level at which the bulk Richardson number exceeds the critical value and linearly interpolate between model levels to establish the exact height at which the bulk Richardson number exceeds this threshold.

Since this is a fully automated method we applied some physical limits to the extent of the boundary layer such that it must be greater than $10 \mathrm{~m}$ and less than $4 \mathrm{~km}$, and values outside of this range were taken to be missing (Seidel et al. 2010). Therefore, we miss some cases of deep convection when the boundary layer turbulence may reach the tropopause, as well as cases of strong, 

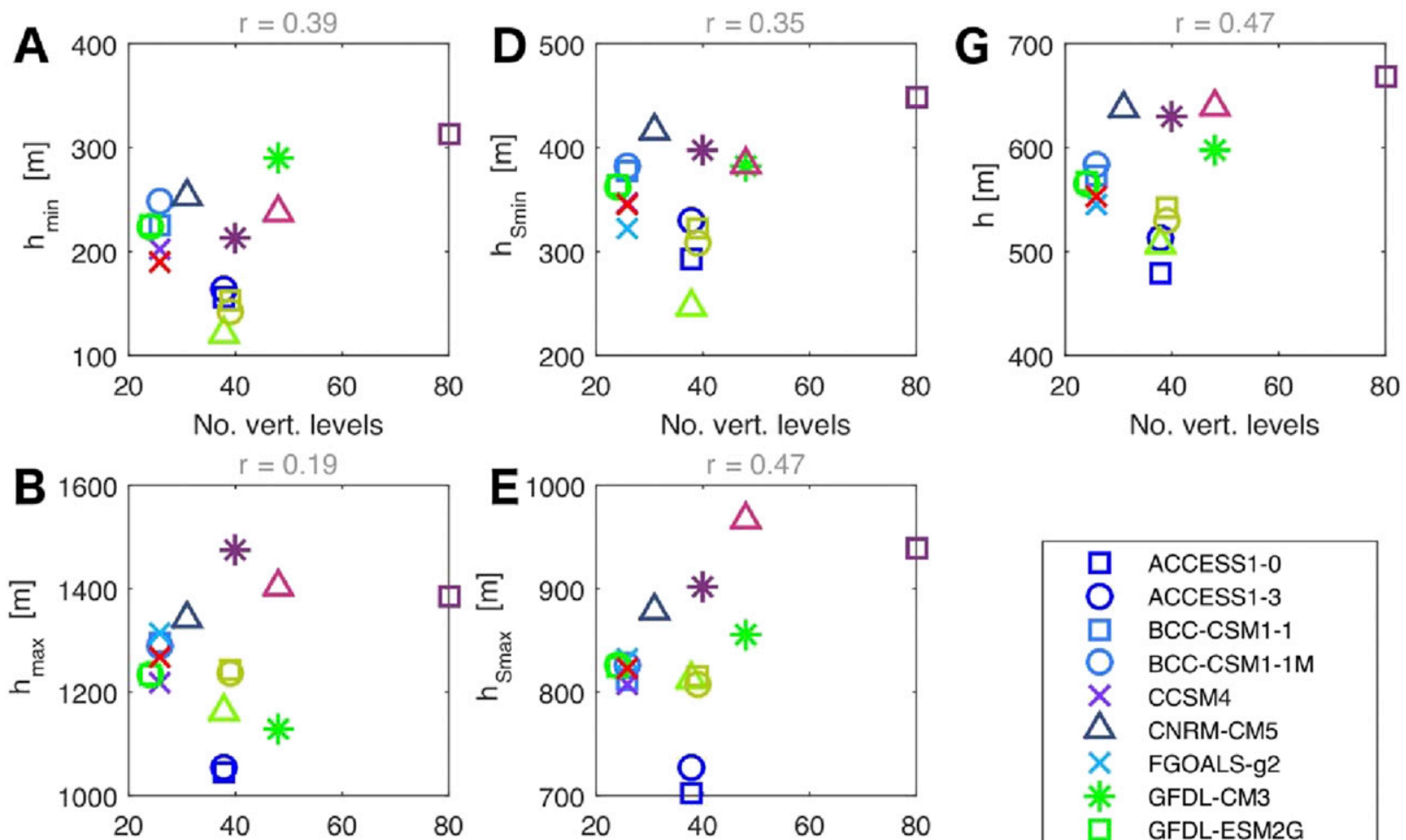

No. vert. levels

No. vert. levels
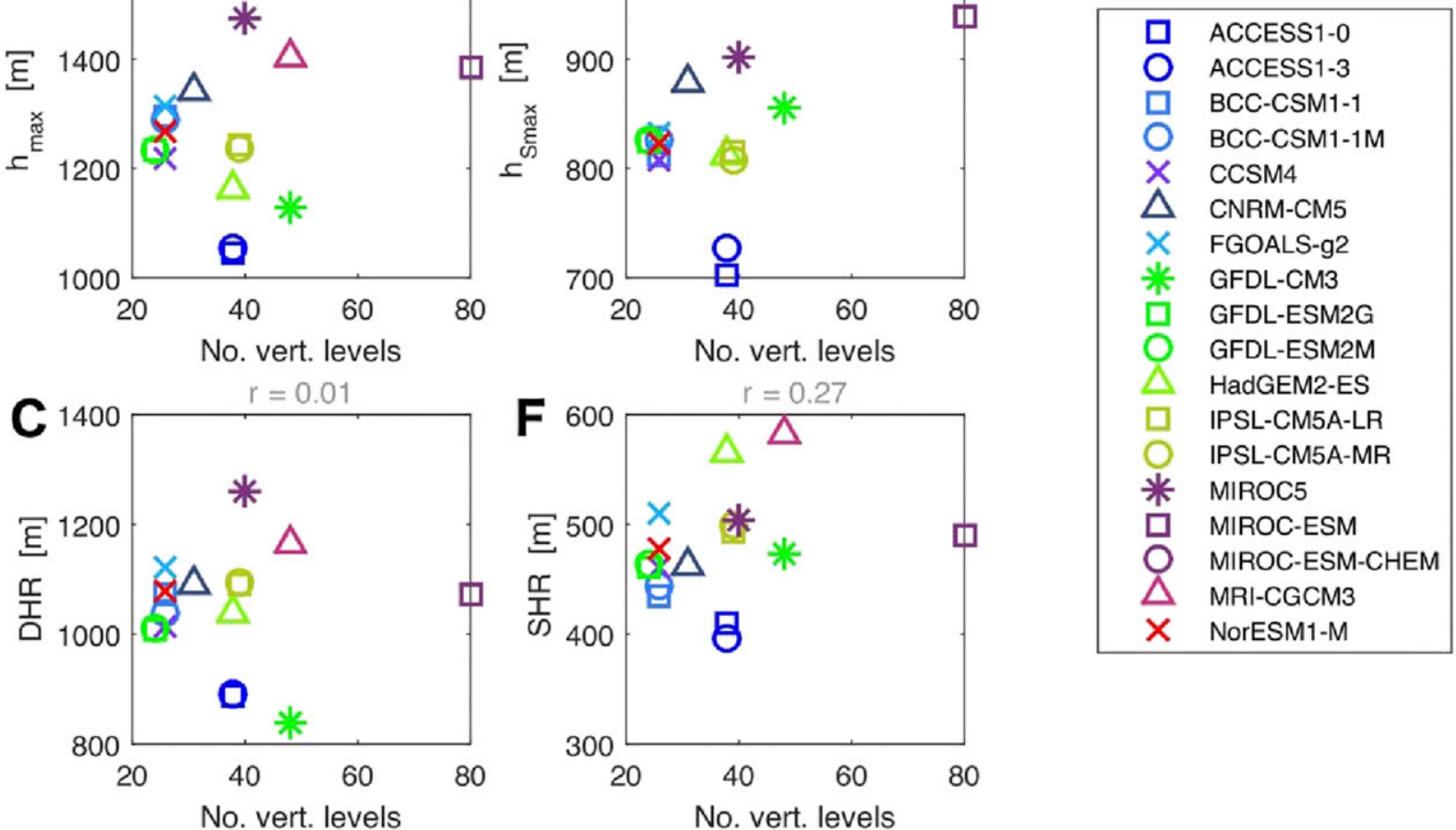

FIG. 3. The intermodel relationship between the number of vertical levels in each model and the climatology of the (a) diurnal minimum, (b) diurnal maximum, (c) DHR, (d) seasonal minimum, (e) seasonal maximum, (f) SHR, and (g) climatological mean PBL depth. The Pearson correlation coefficient is given in the title of each panel in gray if it is not statistically significant with $p<0.05$ and in black if it is statistically significant.

surface-based inversions. There were a moderate percentage of cases for which no PBL depth was found under these constraints: up to $25 \%$ in some locations in the ensemble mean (Fig. S3 in the online supplemental material). Therefore, the method of averaging the PBL depth affected the climatological-mean value. First, we took the mean in each month of each 6-hourly snapshot in order to obtain the average diurnal cycle of the PBL depth for each month. Then, we took the average of each 6-hourly snapshot in each month across all years to obtain the climatological-mean diurnal cycle for each month. Finally, this was averaged to obtain a single climatological-mean value at each location. The diurnal minimum, maximum, and height ranges (DHR) were calculated by averaging the climatological mean of the respective variables over all months. Finally, the seasonal height range (SHR) was calculated by averaging the climatological-mean diurnal cycle in each month and then taking the difference between the maximum and minimum of the monthly values. This averaging method accounted for the fact that this was a noncontinuous time series and ensured equal representation of each 

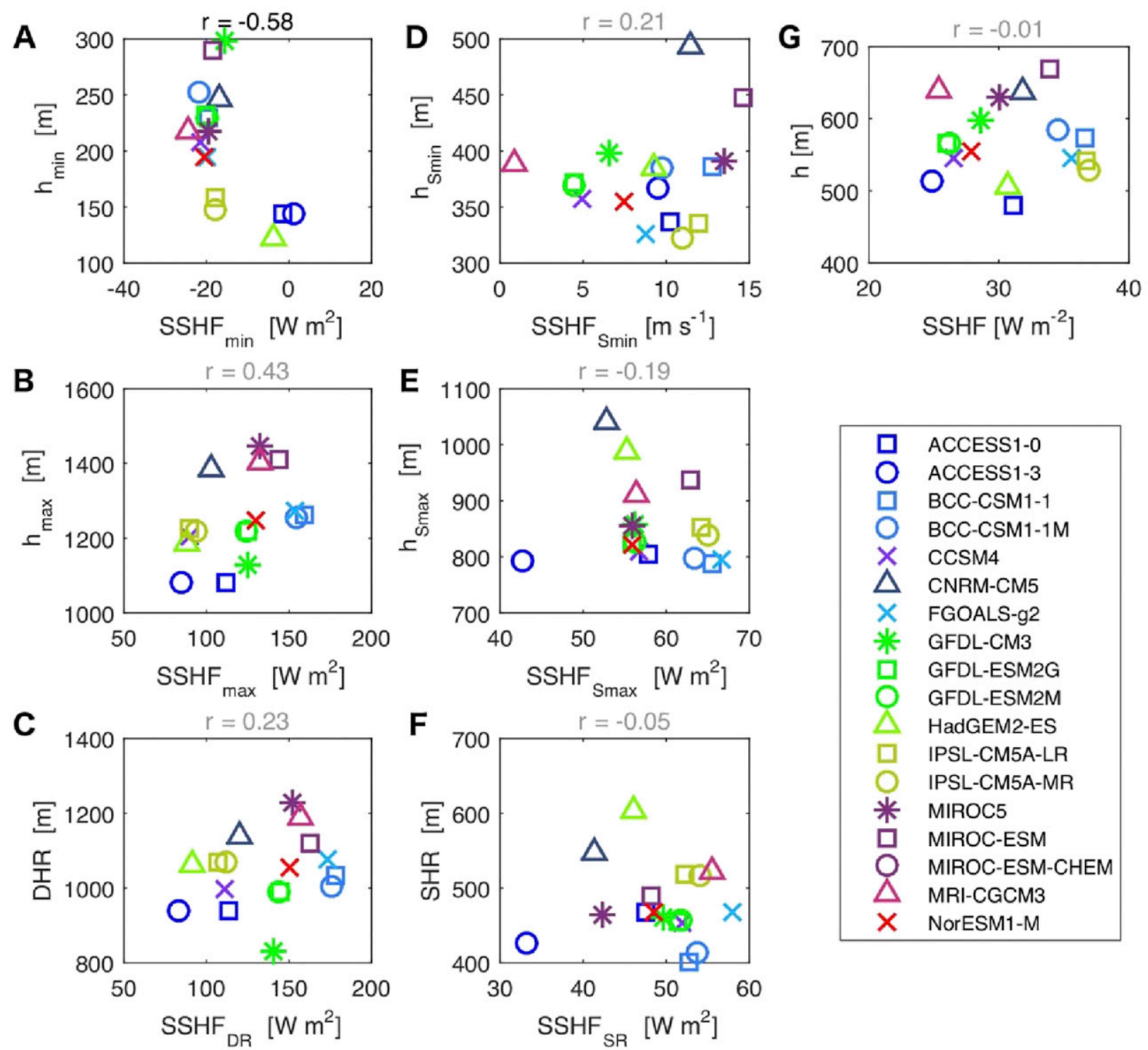

FIG. 4. The intermodel relationship between the surface sensible heat flux in each model and the climatology of the PBL depth at the (a) diurnal minimum, (b) diurnal maximum, (c) DHR, (d) seasonal minimum, (e) seasonal maximum, (f) SHR, and (g) in the climatological mean. The Pearson correlation coefficient is given in the title of each panel in gray if it is not statistically significant with $p<0.05$ and in black if it is statistically significant.

part of the diurnal and annual cycles in the mean climatology.

Our intention here is to assess the global distribution of the mean and range of the PBL depth in contemporary GCMs. Therefore, to assess how consistent the GCM climatologies are with reality, we required a dataset with a high (subdiurnal) temporal resolution and global coverage, which limited us to using a reanalysis product. We chose the ERA-Interim reanalysis produced by ECMWF and the Modern-Era Retrospective Analysis for Research and Applications (MERRA) from the NASA Global Modeling and Assimilation Office. While a reanalysis product such as ERA-Interim cannot be equated to observational data, it is observationally constrained by both surface and lower-atmosphere observations (Dee et al. 2011). Furthermore, evaluation of the PBL depth from ERA-Interim against a variety of observations has shown that the reanalysis captures the spatial and temporal variability reasonably well (Seidel et al. 2012; Ao et al. 2012).

We obtained the forecast field of the PBL depth at a 6-hourly resolution for the period 1979-2005 from the 

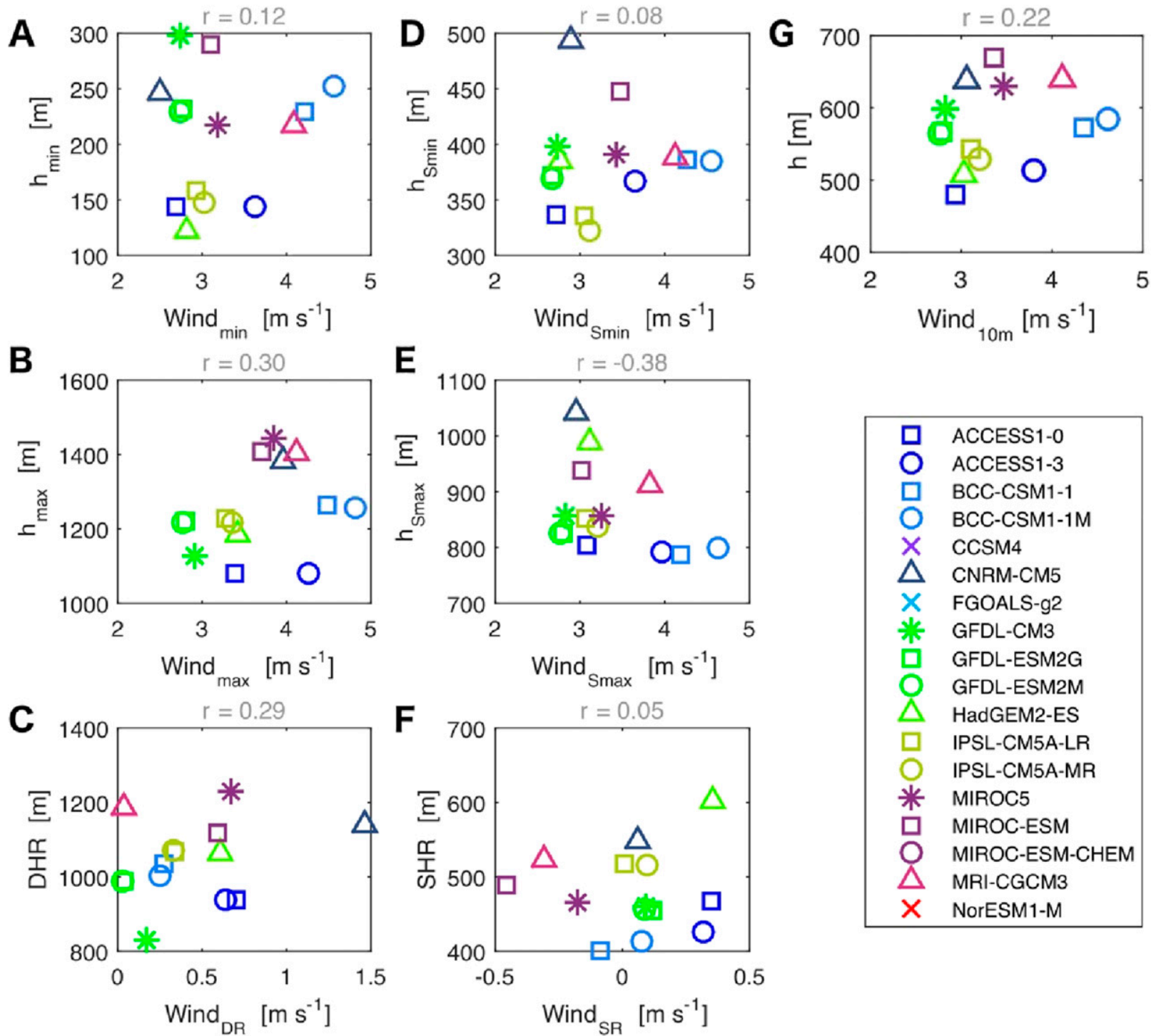

\begin{tabular}{|ll|}
\hline$\square$ & ACCESS1-0 \\
$\bigcirc$ & ACCESS1-3 \\
$\square$ & BCC-CSM1-1 \\
$\bigcirc$ & BCC-CSM1-1M \\
$\times$ & CCSM4 \\
$\triangle$ & CNRM-CM5 \\
$\times$ & FGOALS-g2 \\
$*$ & GFDL-CM3 \\
$\square$ & GFDL-ESM2G \\
$\bigcirc$ & GFDL-ESM2M \\
$\triangle$ & HadGEM2-ES \\
$\square$ & IPSL-CM5A-LR \\
$\bigcirc$ & IPSL-CM5A-MR \\
$*$ & MIROC5 \\
$\square$ & MIROC-ESM \\
$\bigcirc$ & MIROC-ESM-CHEM \\
$\triangle$ & MRI-CGCM3 \\
$\times$ & NorESM1-M \\
\hline
\end{tabular}

FIG. 5. The intermodel relationship between the wind speed at a height of $10 \mathrm{~m}$ above the surface in each model and the climatology of the PBL depth at the (a) diurnal minimum, (b) diurnal maximum, (c) DHR, (d) seasonal minimum, (e) seasonal maximum, (f) SHR, and $(\mathrm{g})$ in the climatological mean. The Pearson correlation coefficient is given in the title of each panel in gray if it is not statistically significant with $p<0.05$ and in black if it is statistically significant.

ECMWF website (http://apps.ecmwf.int/datasets/data/ interim-full-daily/levtype $=\mathrm{sfc} /$ ). Note that since a similar automated method was employed at ECMWF for the calculation of PBL depth in ERA-Interim, there are values of the PBL depth in the reanalysis that exceed $4 \mathrm{~km}$. Therefore, to make a like-for-like comparison, we first removed all values from the ERA-Interim dataset that were outside our imposed range from $10 \mathrm{~m}$ to $4 \mathrm{~km}$. The same averaging procedure as described above was then applied to the reanalysis data. This filtering made very little difference to the climatologies due to the relatively small number of cases of PBL depths outside this range. This process was repeated for the MERRA dataset, which was available from NASA's website (https:// gmao.gsfc.nasa.gov/reanalysis/MERRA-2/).

\section{Ensemble analysis of the PBL climatology \\ a. Mean PBL depth}

The climatological-mean PBL depth from each of the global climate models and the ensemble mean is shown in Fig. 1. One of the most apparent and perhaps surprising results from the ensemble-mean climatology is 


\section{Ensemble mean}
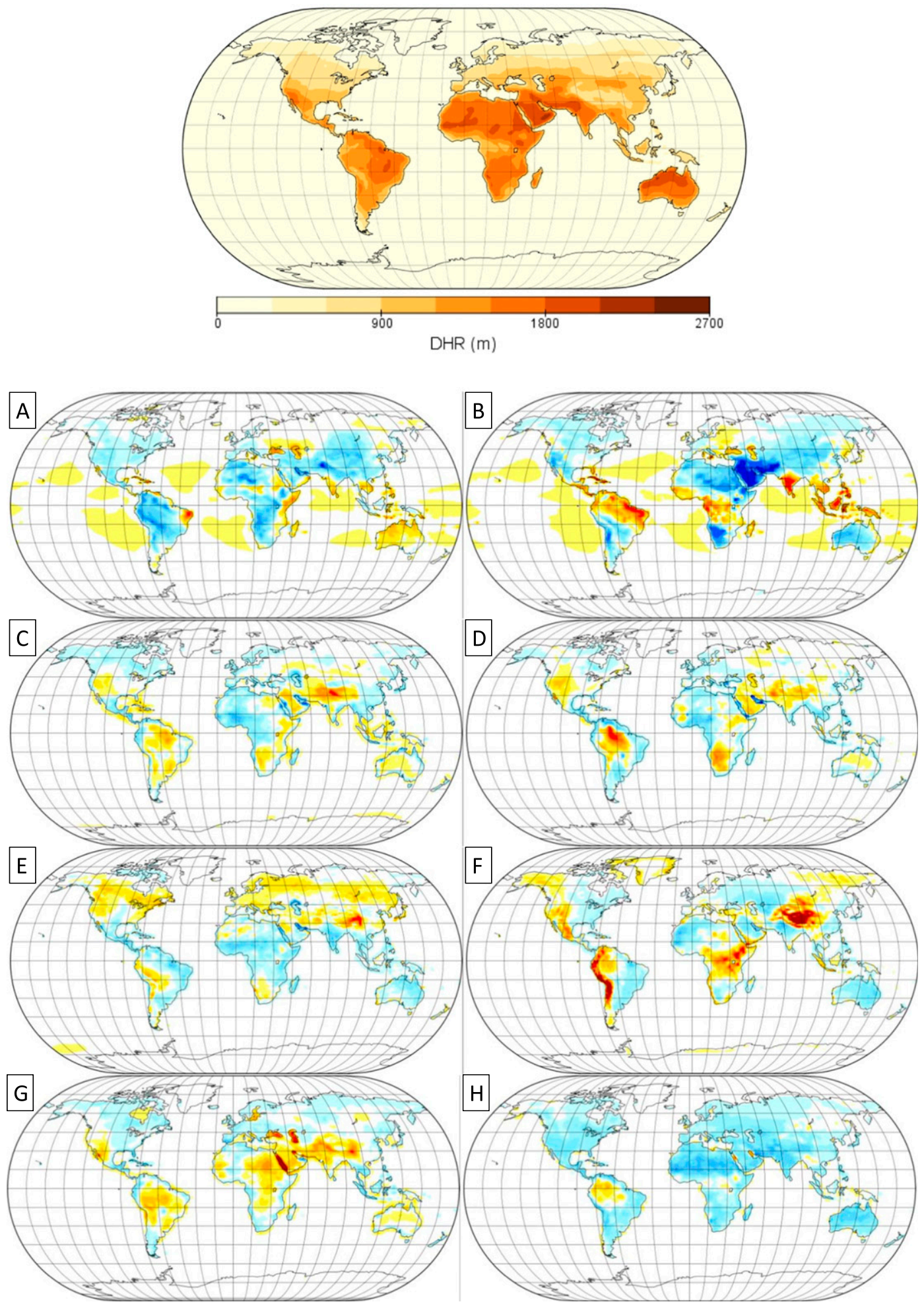

FIG. 6. The climatological-mean DHR (m) from the ensemble mean and the anomalies $\mathrm{DHR}^{\prime}(\mathrm{m})$ with respect to the ensemble mean for each of the models from which the ensemble was comprised. 


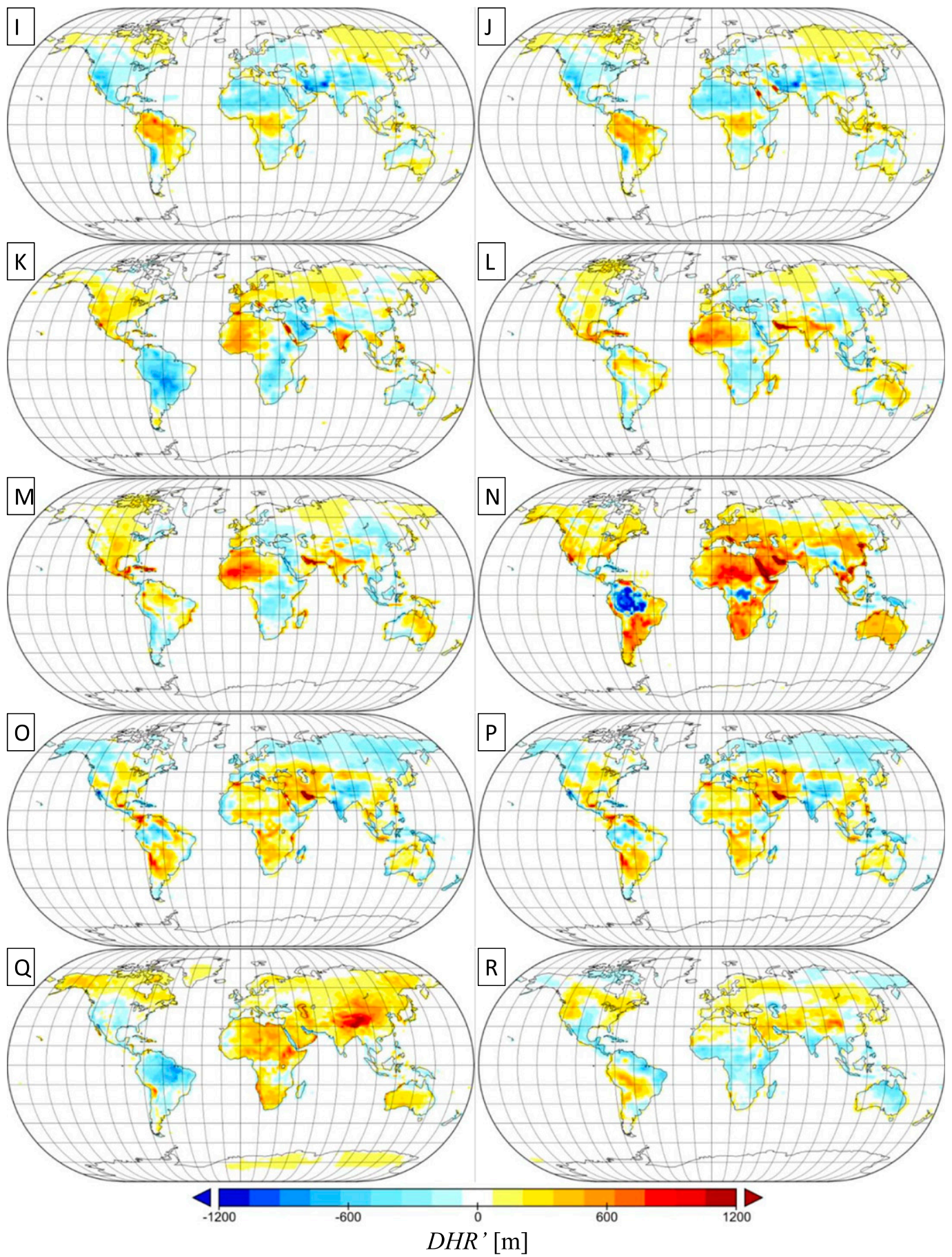

FIG. 6. (Continued)

that we find a deeper PBL over ocean than we do over land. The reason for this is the large diurnal variation in PBL depth over land. During the day when the overland PBL reaches a maximum value, the PBL depth over land is indeed far greater than that found over ocean (Fig. S5). While at night, surface cooling over land leads to stable stratification of the near-surface atmosphere and the formation of shallow PBLs, typically below $200 \mathrm{~m}$, which is far less than the typical overocean PBL depth (Fig. S4). The net result of this large diurnal cycle in PBL depth over land is that the overocean PBL is on average deeper than the PBL over land. This result is 
consistent with previous global analysis of the PBL depth in a global climate model (Medeiros et al. 2005) and the actual values $(800-1200 \mathrm{~m})$ are similar to those found from field campaigns (Stevens 2002; Bretherton et al. 2004). For example, the Eastern Pacific Investigations of Climate (EPIC) field campaign showed a well-mixed boundary layer-a uniform potential temperature and water vapor mixing ratio-with a depth smoothly varying in time from a minimum of around $800 \mathrm{~m}$ up to $1200 \mathrm{~m}$ during the month of October. However, this is of course a small spatiotemporal sample and a thorough model-observation comparison is needed to determine how well the models are performing in simulating the overocean mixed layer (Bretherton et al. 2004).

The ensemble-mean climatology shows some of the most common features from the climatologies of the individual models: the deepest overland PBL is in lowlatitude desert regions where in the ensemble mean the average depth is in excess of $600 \mathrm{~m}$ and the shallowest layers are found in the high latitudes and altitudes; for example, the average PBL depth across Antarctica and the Arctic basin is less than $300 \mathrm{~m}$ in the ensemble mean. However, there are large differences between the individual models as to the global-mean and the geospatial pattern of the PBL depth. In a given model the climatological-mean depth can vary from less than $100 \mathrm{~m}$ over Antarctica, Greenland, and the rest of the Arctic to more than $1500 \mathrm{~m}$ over the Horn of Africa, the northeast coast of South America, and/or southwest Asia. There are generally strong similarities in the geospatial patterns of PBL height in models coming from the same center for example, the two versions of MIROC-ESM and the two versions of the GFDL-ESM. However, owing to the numerous changes in the atmospheric model, the ACCESS1.0 and ACCESS1.3 results are distinctly different, especially in the tropics (Fig. 1). Global climate models generally perform poorly in regions of steep orography irrespective of the underlying parameterization schemes employed (Lindvall and Svensson 2015). Consequentially, there can be large differences in the mean PBL depth in mountainous regions, as exemplified by the MRI-CGCM3 model and the MIROC models.

The degree of variability within the ensemble in the climatological-mean PBL depth, and its geospatial pattern, can be seen in Fig. 2. This shows both the standard deviation in climatological-mean PBL depth within the ensemble, and the ensemble standard deviation normalized by the ensemble-mean PBL depth. Generally, there is a reasonable agreement between the models with a standard deviation in the ensemble of less than $20 \%$ over much of the land and less than $30 \%$ almost everywhere around the globe. The most prominent regions with the largest differences between the models are the northeast coast of South America, the desert regions of North America, and south-central Asia including the Tibetan Plateau. The Tibetan Plateau stands out as a region of particularly high relative spread in the models (Fig. 2b). In this region there is a stark separation between the models, with 10 models producing shallow PBLs $(<400 \mathrm{~m})$ and the remainder showing deep PBLs $(>800 \mathrm{~m})$. While other regions have relatively large spreads of a few hundred meters, almost all the models agree that these are regions of relatively deep boundary layers (Fig. 1), so the normalized spread is relatively small (less than $30 \%$ ).

One might expect that the vertical resolution in the models is important in determining the climatology of the boundary layer, given that many model analyses have shown in single-column experiments that higher vertical resolution leads to a better representation of boundary layer turbulence (Cuxart et al. 2006). However, here we see no statistically significant relationship between the models in their vertical resolution and their mean overland PBL climatology (Fig. 3). However, a gridpoint-wise correlation analysis showed many overland regions with a strong positive relationship: so those models with a higher vertical resolution have a deeper mean PBL (Fig. S6). While there was no relationship between the mean overland climatological-mean surface sensible heat flux and the mean PBL depth in the models (Fig. 4), a gridpoint-wise correlation analysis did indeed show a strong positive relationship at many overland locations, as expected. This analysis also showed a strong negative relationship over most of the ocean in the tropics. There is no significant relationship between the overland climatological-mean wind speed and PBL depth between the models (Fig. 5), although there is a strong positive relationship over the oceans (Fig. S6).

\section{b. Diurnal cycle in PBL depth}

The climatological mean of the PBL DHR from each of the global climate models and the ensemble mean are given in Fig. 6. In the ensemble mean we can see that the largest DHRs with values in excess of $1500 \mathrm{~m}$ are found in the extratropical desert regions of Africa, Australia, and the Arabian Peninsula. As expected, there is a negligible DHR in the polar regions and over the ocean due to the lack of a diurnal cycle in incoming radiation and the atmospheric response on the diurnal variations in forcing, respectively. All models reproduce this feature of the DHR. The geographical pattern of DHR in individual models matches well to the pattern of the climatological-mean PBL depth (Fig. 1); that is, those 

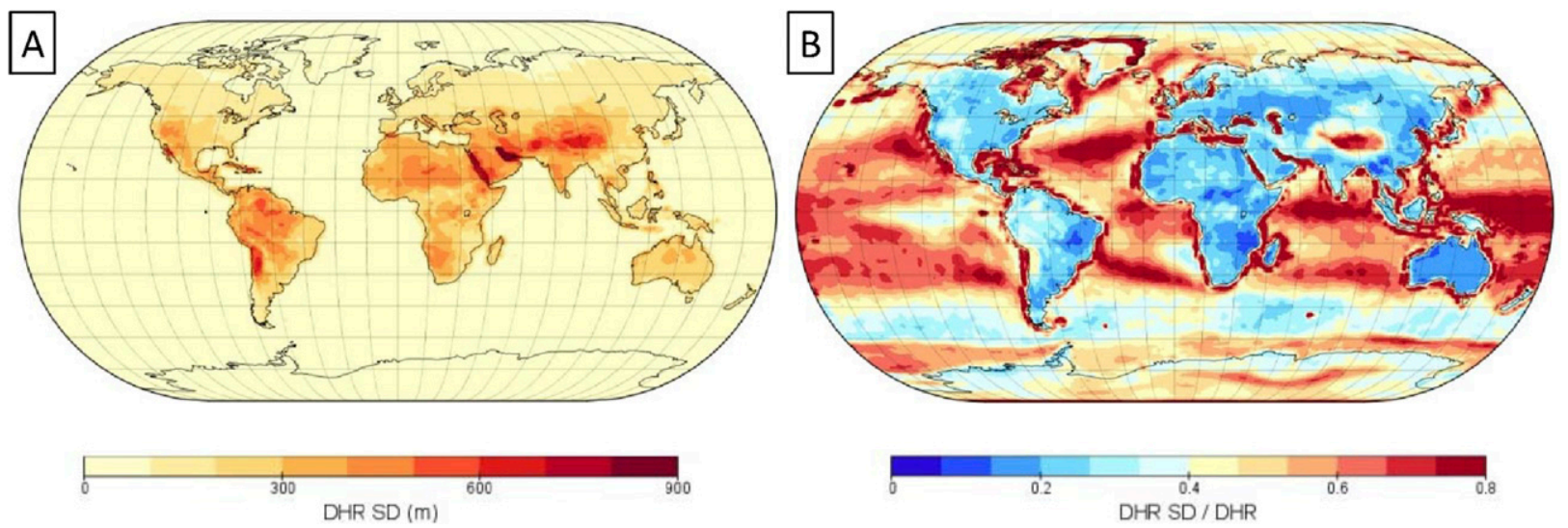

FIG. 7. (a) The standard deviation of the DHR ( $\mathrm{m}$ ) in the ensemble and (b) the ensemble standard deviation normalized by the ensemblemean DHR.

locations with a high DHR generally have deeper PBLs in the climatological mean. Most models have some region(s) with very high DHRs in excess of $2500 \mathrm{~m}$, generally in the extratropical desert regions, but since the exact locations of these high DHRs vary considerably between models, such high DHRs are not seen in the ensemble-mean climatology.

As with the climatological-mean PBL depth there is also a high degree of similarity in the climatologies of the two MIROC-ESM simulations and the two GFDL-ESM model results. And here we can also see some substantial differences between the ACCESS1.0 and ACCESS1.3 models in their climatologies of the DHR. The two versions of the ACCESS model had substantial changes to the atmospheric physics component, which made the biggest difference in the tropics ( $\mathrm{Bi}$ et al. 2013). However, there seems to be no influence of horizontal resolution on the climatology of the DHR, as seen in the two IPSL model climatologies.

Figure 7 a shows the standard deviation of the DHR in the ensemble, and Fig. 7b shows the ensemble spread normalized with respect to the ensemble mean. The spread is less than $400 \mathrm{~m}$ across most of the globe and generally less than $200 \mathrm{~m}$ in the mid- to high latitudes. This corresponds to a less than $20 \%$ spread in the DHR across most of the globe and a less than $40 \%$ spread everywhere except for over the Tibetan Plateau. Here, again, we have a dichotomy in the models with many models showing a very small diurnal cycle in this region $(<300 \mathrm{~m})$ but a few models having extremely large diurnal height ranges, greater than $2.4 \mathrm{~km}$. Hence, the relative spread in the model DHR in this region is close to $100 \%$ of the ensemble mean. Global climate models have difficulty in representing the PBL depth in highaltitude plateau regions which is most apparent in their representation of deep PBLs during the daytime and summertime (Figs. S5 and S7) than in the representation of shallow PBLs found at night and during the winter (Figs. S4 and S7). The unique conditions of the Tibetan Plateau make it an exceptional challenge for models to reproduce the PBL in the region as the PBL can grow exceptionally deep not just because of the dry surface and high sensible heat flux but because of the low stability of the free atmosphere (Chen et al. 2016). Observation-based estimates of the PBL depth over the Tibetan Plateau have shown that we get deep, greater than 2-km, daytime PBLs at all times of year (Liu et al. 2015), but very few models reproduce this deep daytime PBL.

In the overland climatological mean, neither the wind speed nor the vertical resolution explains the variations in the components of the overland mean diurnal cycle in PBL depth (Figs. 3 and 5). There is a statistically significant relationship between the overland mean of the surface sensible heat flux and PBL depth at the diurnal minimum (Fig. 4). However, there is a clear separation between the models, with most of the models having a sensible heat flux at the diurnal minimum close to $-20 \mathrm{~W} \mathrm{~m}^{-2}$ and three having sensible heat fluxes close to $0 \mathrm{~W} \mathrm{~m}^{-2}$. So this statistical relationship should be treated with caution. The gridpoint-wise correlation analysis confirmed the lack of an intermodel relationship between the diurnal cycle in PBL depth (minimum, maximum, and range) and the corresponding wind speeds at most locations, although the strong positive correlation between the diurnal minimum climatologies over the Tibetan Plateau might explain some part of the large intermodel spread there (Fig. S6). The gridpoint analysis did reveal the strong positive correlation between vertical resolution and diurnal minimum PBL depth across much of the land surface. This might be expected given that the shallow nocturnal 


\section{Ensemble mean}
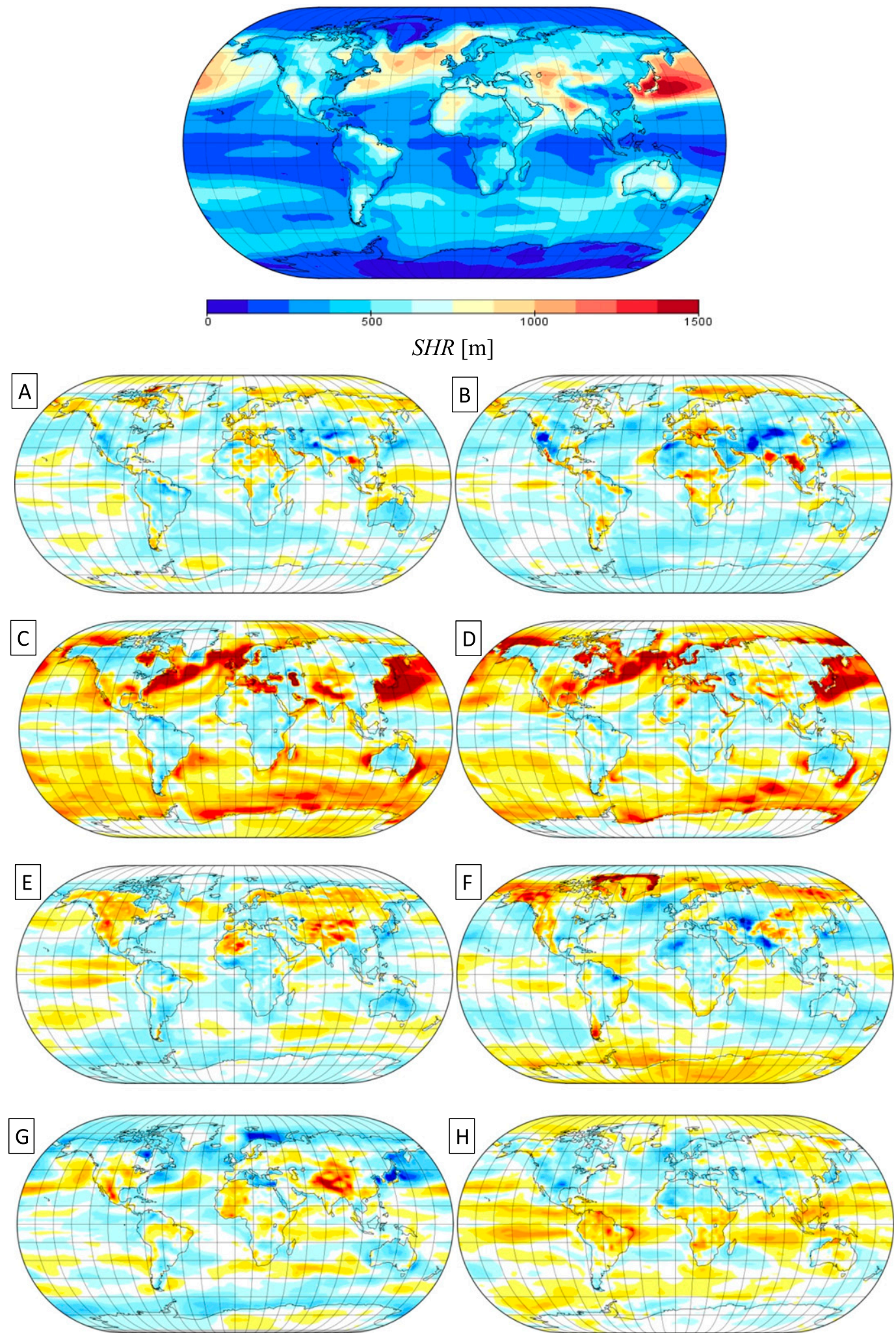

FIG. 8. The SHR of the PBL depth (m) from the ensemble mean and the anomalies $\mathrm{SHR}^{\prime}(\mathrm{m})$ with respect to the ensemble mean for each of the models from which the ensemble was comprised. 

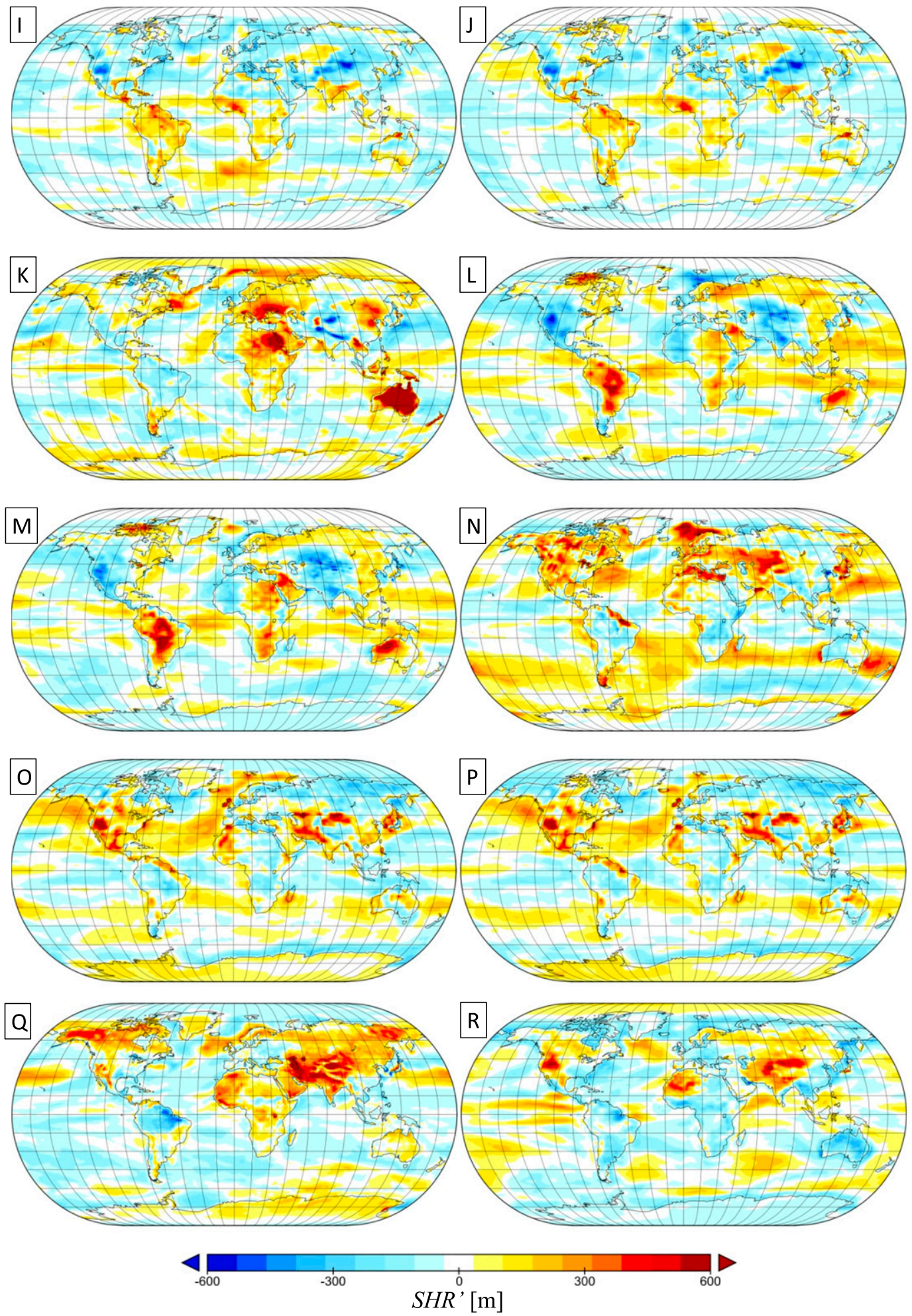

FIG. 8. (Continued) 

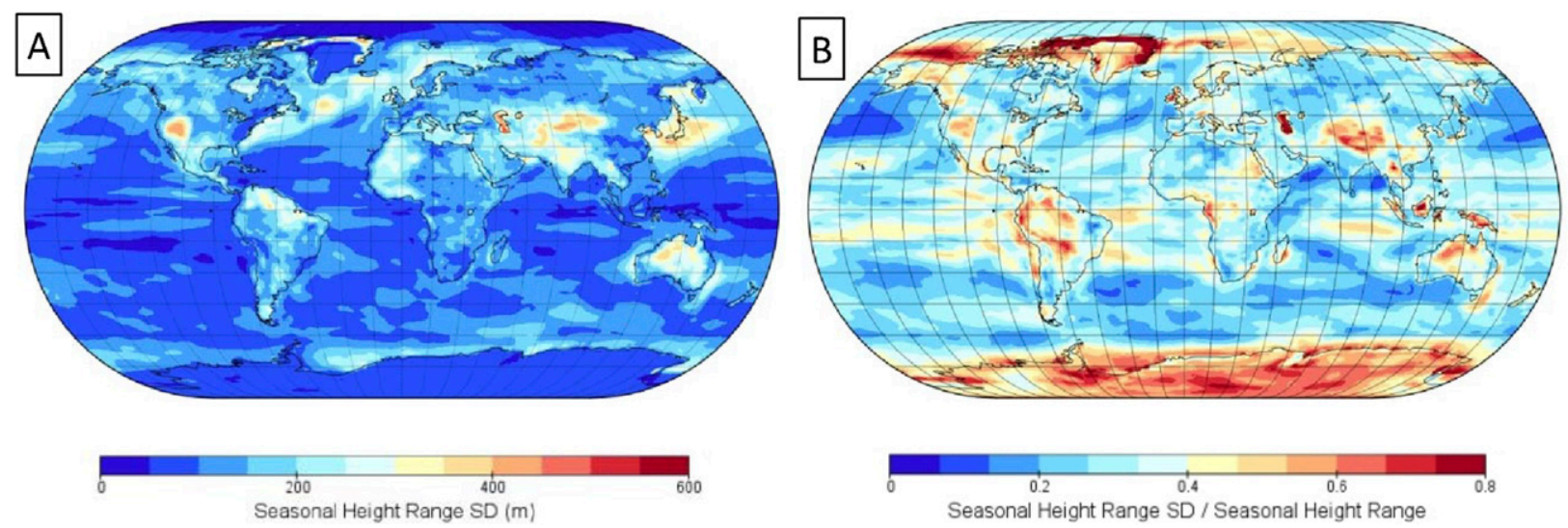

FIG. 9. (a) The standard deviation in the ensemble of SHR in PBL depth (m) and (b) the ensemble standard deviation normalized to the ensemble mean at each location.

PBL has a depth typically at or below the first model level, so vertical resolution becomes extremely important when it comes to capturing these shallow boundary layers. There is also a significant, positive correlation between the surface sensible heat flux and the PBL depth at the diurnal maximum in many places overland including the Sahara Desert and much of South America (Fig. S6).

\section{c. Seasonal cycle in PBL depth}

The SHR in each of the models and in the ensemble mean is given in Fig. 8. This is defined as the largest difference in the climatological monthly mean PBL depth at each location. In the ensemble mean the overland SHR ranges from less than $100 \mathrm{~m}$ to over $1000 \mathrm{~m}$ in northern India. However, individual models show considerably more variation, with several models having SHRs in excess of $1500 \mathrm{~m}$ in some desert regions. In all the models it is in these desert regions that we find the greatest overland SHR owing to the low soil moisture content such that the seasonal variations in surface forcing have a large impact on the surface sensible heat flux and, thus, the PBL depth. We also find a large SHR over the ocean in the storm track of the North Atlantic and in the northwest Pacific. This is linked to the wintertime advection of cold air from the continents over the ocean, which creates a strong temperature gradient between the ocean and atmosphere. This temperature difference triggers intense fluxes and the formation of deep PBLs and the formation of stratocumulus clouds. The SHR is therefore strongly linked to the seasonal cycle in cloud cover (Klein and Hartmann 1993; Karlsson and Teixeira 2014). We can therefore expect that differences between individual models in the SHR over ocean are linked to the intensity of the air-sea temperature differences and correspondingly the frequency of marine stratocumulus (Hannay et al. 2009). The model with the largest difference in comparison to the ensemble mean, the BCC_CSM, has known biases in the simulation of stratocumulus linked to its representation of the PBL (Wang et al. 2014).

This large difference between the SHR climatologies in the models can be seen in the ensemble spread (Fig. 9). There are a few regions where the standard deviation in the ensemble SHR is greater than $300 \mathrm{~m}$, principally in the deserts of China, the United States, and Australia. Once again, the Tibetan Plateau stands out as a region of large relative spread in the model ensemble owing to a division in the models with most producing very small SHRs in this region, but a few models with large SHRs lead to a large absolute and relative spread.

None of the variables investigated-the wind speed, vertical resolution, or surface sensible heat flux-could explain the differences in the overland average of the components of the seasonal cycle in the PBL depth between the models (Figs. 3-5). However, as with the diurnal minimum, there are many overland locations including Australia, much of Africa, and South America where there is a significant positive correlation between vertical resolution and the seasonal minimum PBL depth (Fig. S6). There were also many overocean locations where there is a strong positive correlation between the seasonal minimum wind speed and PBL depth in the models, including the whole of the Arctic Ocean. This is to be expected given that over the sea ice in the Arctic winter there are only weak surface heat fluxes and so differences in PBL depth are mostly driven by differences in the wind speed.

\section{Comparison of the climate model PBL climatologies to the ERA-Interim and MERRA reanalyses}

The ensemble mean of the climatological-mean PBL depth (Fig. 10a) has a similar geographical pattern to that found in the ERA-Interim reanalysis (Fig. 10b), but 

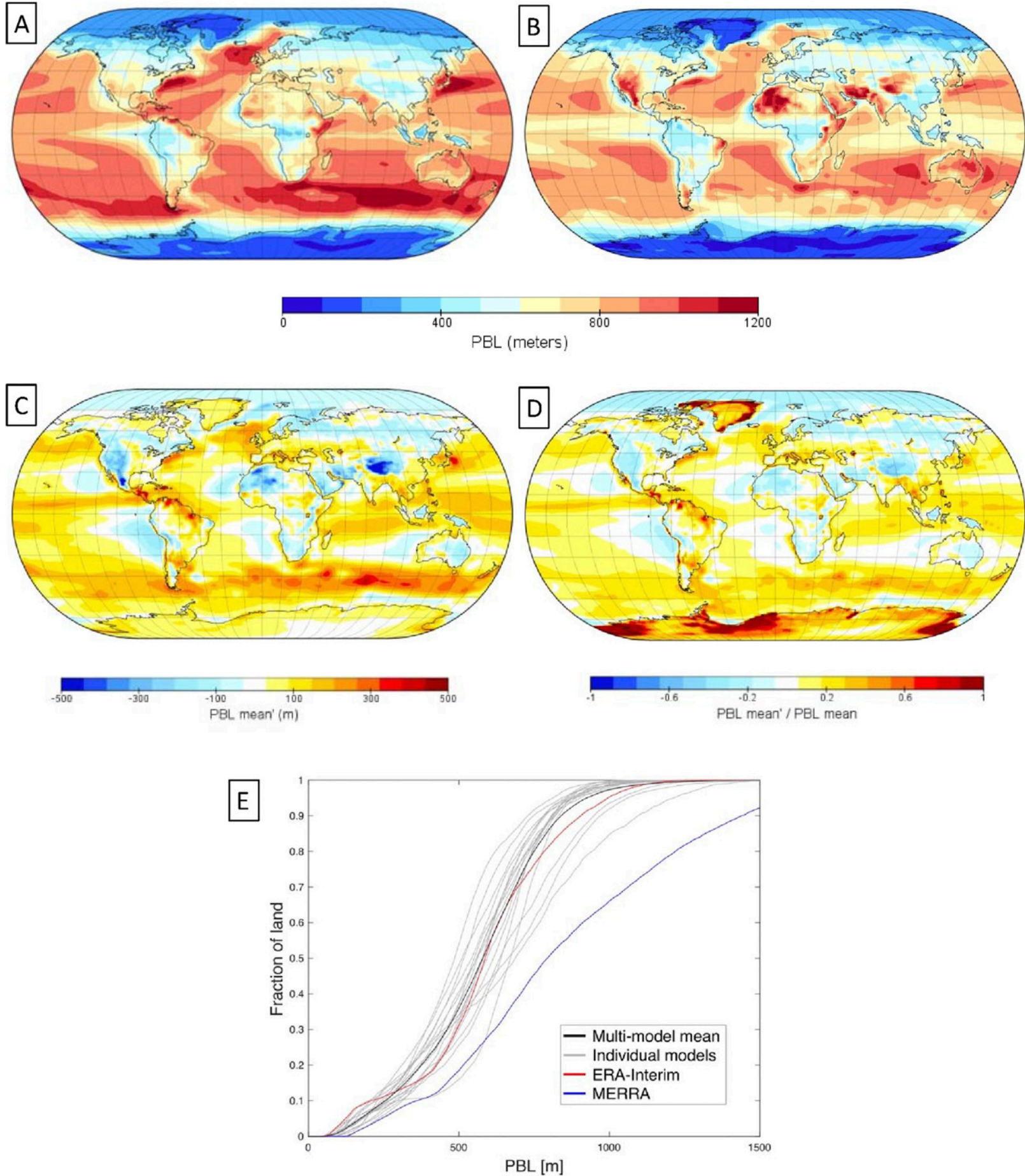

FIG. 10. The climatological mean PBL depth from (a) the ensemble mean of the models and (b) ERA-Interim with (c) the difference between the two climatologies (ensemble mean - ERA-Interim) and (d) the normalized difference between the two climatologies [(ensemble mean - ERA-Interim)/ERA-Interim]. (e) The cumulative probability distribution function for the climatological-mean PBL depth given as s fraction of land covered for each of the individual models (gray), the ensemble mean value (black), the ERA-Interim reanalysis (red), and the MERRA reanalysis (blue). 
the deepest layers in the reanalysis over the western Sahara, North America, and southern Asia are not reproduced in the ensemble mean. This can be seen in the bias of the ensemble mean with respect to the ERAInterim reanalysis (Fig. 10c), where there are large biases of up to $500 \mathrm{~m}$ in the desert regions of North America, Africa, and southern Asia. Since these are all regions of deep boundary layers, the relative biases remain small across much of the globe (Fig. 10d) and are generally less than $20 \%$. Some important exceptions are found in the coastal regions of Antarctica and Greenland, where the very shallow boundary layers in the reanalysis in these regions of $<100 \mathrm{~m}$ are not captured by the models, leading to very large relative biases.

While the ensemble mean clearly has strong negative biases in desert regions, it is important to note that the pattern of mean PBL depth varied considerably between the models and many did produce the deep boundary layers seen in the ERA-Interim reanalysis, if not necessarily in the same locations. Therefore, it can be informative to look at the distribution of PBL depths in the models, as compared to the reanalyses (Fig. 10e). When we compare the distributions, we can see that the climatology from the ERA-Interim reanalysis generally lies well within the range of distributions found in the model ensemble, although the ERA-Interim reanalysis does have more of the very shallow layers, less than $200 \mathrm{~m}$, than is found in any of the models. The MERRA reanalysis on the other hand lies well outside of this range. In this reanalysis there are no mean PBL depths of less than $150 \mathrm{~m}$, and there are much deeper climatological-mean PBLs in MERRA than in either ERA-Interim or the climate models.

The climatological mean of the DHR is generally much lower in the ensemble mean (Fig. 11a) than in the ERA-Interim reanalysis (Fig. 11b). This is reflected in the bias of the ensemble mean with respect to the ERAInterim reanalysis, which shows a lower diurnal cycle in the ensemble mean across most of the globe (Figs. 11c,d). The only exception to this is in South America, where in the ensemble mean there is a relatively large DHR, in excess of $900 \mathrm{~m}$ in large parts of the center and northwest of the continent, which is not produced in the ERAInterim reanalysis. The other region with a very strong bias is the Tibetan Plateau. In the ERA-Interim reanalysis there is a very strong DHR in this region in excess of $2100 \mathrm{~m}$. While this was seen in some models, it was not a common feature and so is not seen in the ensemble mean.

When we compare the distribution of the overland DHR in the individual models and in the reanalyses we can see this overall bias toward a reduced DHR in the models relative to ERA-Interim, especially in the upper range of the DHRs (Fig. 11e). For example, only one of the models has DHRs greater than $2500 \mathrm{~m}$ anywhere around the globe, whereas in the ERA-Interim reanalysis these are found over about $5 \%$ of the land. However, this may be due to uncertainty in the reanalysis products. The MERRA reanalysis has fewer of the shallow DHRs, below $1500 \mathrm{~m}$, than is seen in the models, but it has none of the deep DHRs seen in the ERA-Interim reanalysis. This overall damped diurnal cycle in the models relative to ERA-Interim is a combination of both deeper boundary layers at the diurnal minimum and shallower boundary layers at the diurnal maximum (Figs. S4 and S5). But in contrast, the MERRA reanalysis has far deeper boundary layers at the diurnal minimum than is found in the models, with an average difference of around $200 \mathrm{~m}$. The diurnal maximums in MERRA are more similar to those found in ERA-Interim (Figs. S4 and S5).

The comparison between the climatology of the SHR in the climate models and the reanalyses is given in Fig. 12. While some individual models did reproduce the strong SHR over West Africa as is seen in ERAInterim (Fig. 12b), this was not a common feature in the ensemble (Fig. 12a) and so the ensemble-mean SHR showed a strong negative bias in this region (Fig. 12c). We also see negative biases, corresponding to a consistent underestimation of the SHR with respect to ERAInterim, over the desert regions of the western United States and over the Tibetan Plateau. Since these are all regions of relatively large SHR in ERA-Interim, the relative bias in these regions is small (Fig. 12d). However, the relatively large SHR over northern South America that is found in most of the models is not present in ERA-Interim. This is one of the few regions where the models have a positive bias in the SHR, with the ensemble-mean SHR being more than double that of ERA-Interim in some parts of the continent (Fig. 12d).

Overall, the models have a damped seasonal cycle in PBL depth with respect to both reanalyses, as can be seen from the cumulative probability distribution function of SHR for the individual models and the reanalyses (Fig. 12e). The distribution of SHR in the reanalyses generally lies at the upper limit, or even outside of the range found in the ensemble. This is mostly due to the models producing much deeper boundary layers at the seasonal minimum as compared to ERA-Interim, while MERRA has far greater seasonal maxima than is found in either the models or ERA-Interim, while the distribution of the seasonal maximum depths in the models shows good agreement with ERA-Interim (Figs. S7 and S8).

\section{Conclusions}

An assessment of the climatological mean and the diurnal and seasonal cycles of the PBL depth from 18 

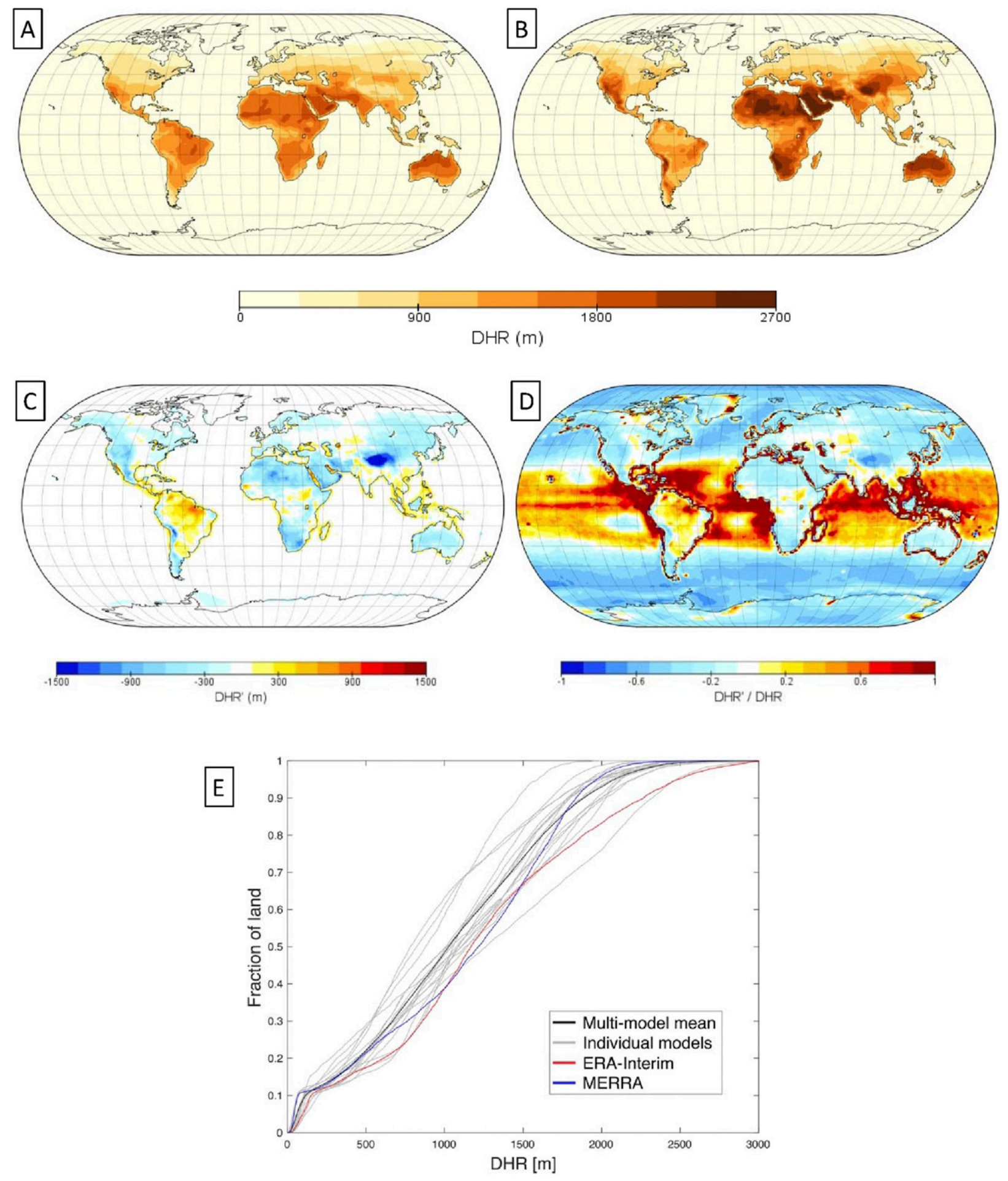

FIG. 11. As in Fig. 10, but for the climatological mean in the diurnal range in the PBL depth.

global climate models is presented. The climate models are in good agreement with the ERA-Interim reanalysis regarding the frequency distribution of mean PBL depth, although the geographical pattern of mean PBL depth varies considerably between models. This overall good match to the annual-mean climatology from the ERA-Interim reanalysis may be a consequence of the efforts of modeling centers to tune these climate models 

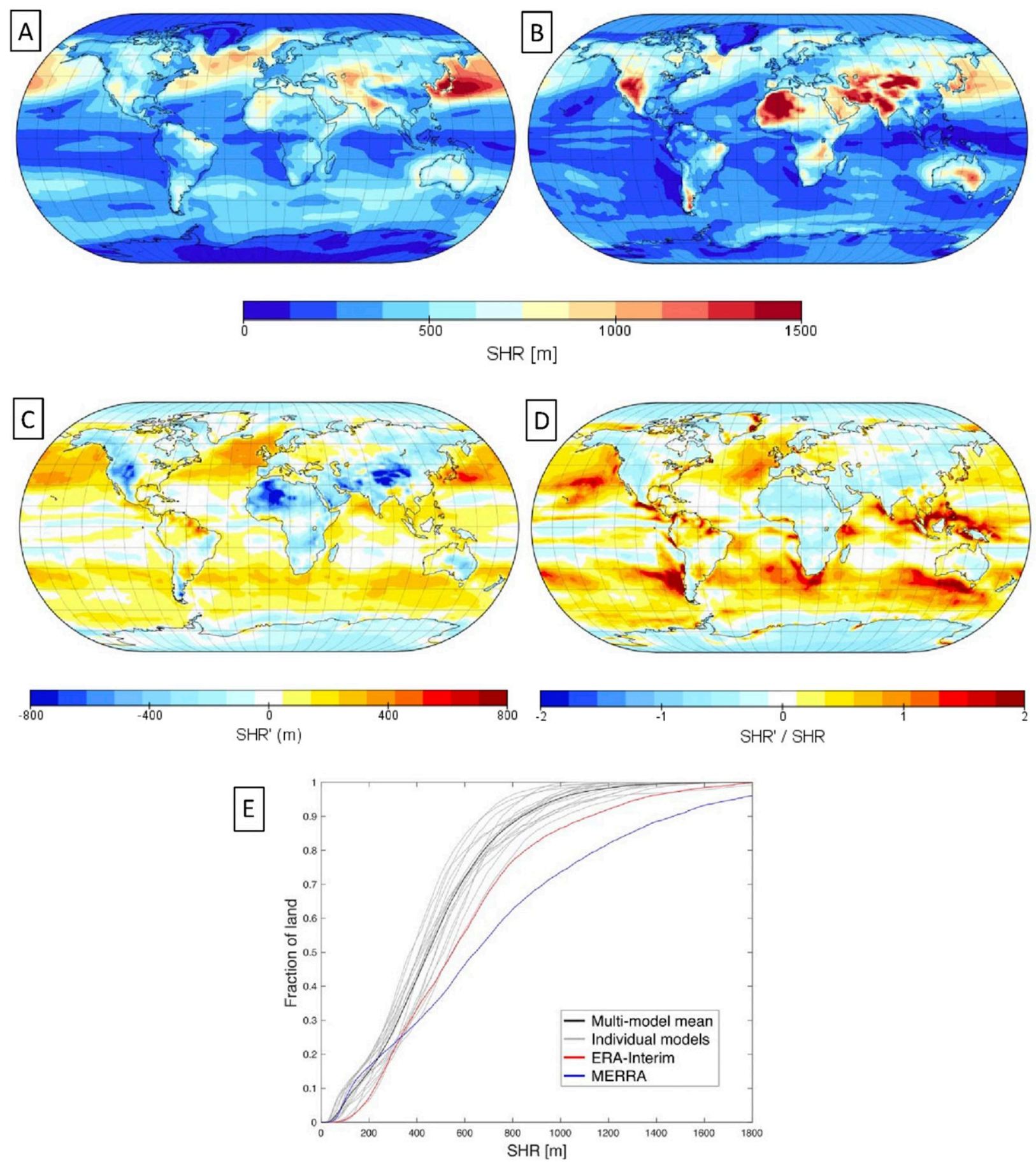

FIG. 12. As in Fig. 10, but for the climatological mean in the seasonal range of the PBL depth.

toward a close representation of, among other variables, the global-mean SAT (Mauritsen et al. 2012), given that there is a close correlation between the local mean SAT and PBL depth, at least in convective boundary layers (McGrath-Spangler and Molod 2014). However, the large difference between the PBL climatologies in MERRA and ERA-Interim suggests that reanalysis products should be used with caution in the assessment of PBL depth. Although the unfeasibly deep nocturnal PBLs in desert regions within MERRA suggest that the PBL depth may not be reliable in this product.

Overall, the models have a reduced diurnal cycle as compared to the ERA-Interim reanalysis almost everywhere around the globe due to a combination of a 
general overestimation of the diurnal minimum PBL depth and underestimation of the diurnal maximum PBL depth. The ensemble spread (standard deviation) in the diurnal minimum PBL depth is especially large with spreads in excess of $100 \%$ of the ensemble-mean value. The well-known issues with the parameterization of the stably stratified boundary layer within climate models are likely to be the cause of this large spread in the models' PBL depth at the diurnal minimum (Mahrt 2014; Holtslag et al. 2013). This large uncertainty in the depth of the stably stratified boundary layer has been shown to have a large influence on the representation of the diurnal and seasonal cycles in the models, as well as their sensitivity to changes in external forcing (Holtslag et al. 2013; Davy and Esau 2014; Wei et al. 2017).

A similar issue arises with the seasonal range in the PBL depth: there is a damped seasonal cycle in the models as compared to the ERA-Interim reanalysis owing to a tendency to overestimate the seasonal minimum depth and underestimate the seasonal maximum PBL depth. The large spread in the models and general positive bias in the seasonal minimum PBL depth is likely also related to the representation of the stably stratified boundary layer in these models (Holtslag et al. 2013). Given that the sensitivity of the SAT to changes in forcing is especially high in these stably stratified boundary layers (Davy and Esau 2016), it is important to improve the representation of the diurnal and seasonal cycles of the PBL depth if these models are to more reliably describe changes in the diurnal and seasonal SAT cycles that have been observed (Cohen et al. 2012; Davy et al. 2017). The climatology of the PBL depth in a large ensemble of global climate models, as presented here, will be a useful tool in assessing the importance of the model depiction of vertical mixing on the resultant surface climate.

Several recent studies have investigated the impacts of the representation of the boundary layer within global climate models on the surface climate and climate change (Davy and Esau 2014; Wei et al. 2017). However, without a climatology of the PBL depth they have relied instead on various proxies to characterize the vertical mixing in the models, each of which has its own limitations. The dataset presented here is a new tool for those interested in the characterization and assessment of PBL processes and atmosphere-surface coupling in these global climate models.

Acknowledgments. We acknowledge the World Climate Research Programme's Working Group on Coupled Modelling, which is responsible for CMIP, and we thank the centers listed in Table 1 of this paper for producing and making available their model output. For CMIP the U.S. Department of Energy's Program for
Climate Model Diagnosis and Intercomparison provides coordinating support and led development of software infrastructure in partnership with the Global Organization for Earth System Science Portals. This work was supported by the Bjerknes Centre for Climate Research project BASIC. This research was supported by the Blue-Action Project (European Union's Horizon 2020 Research and Innovation Programme, Grant 727852).

\section{REFERENCES}

Akimoto, H., 2003: Global air quality and pollution. Science, 302, 1716-1719, https://doi.org/10.1126/science.1092666.

Angevine, W. M., 2008: Transitional, entraining, cloudy, and coastal boundary layers. Acta Geophys., 56, 2-20, https://doi.org/ 10.2478/s11600-007-0035-1.

Ao, C. O., D. E. Waliser, S. K. Chan, J. L. Li, B. Tian, F. Xie, and A. J. Mannucci, 2012: Planetary boundary layer heights from GPS radio occultation refractivity and humidity profiles. J. Geophys. Res., 117, D16117, https://doi.org/10.1029/2012JD017598.

Arya, S. P., 1999: Air Pollution Meteorology and Dispersion. Oxford University Press, 320 pp.

Beare, R. J., and Coauthors, 2006: An intercomparison of large-eddy simulations of the stable boundary layer. Bound.-Layer Meteor., 118, 247-272, https://doi.org/10.1007/s10546-004-2820-6.

Bentsen, M., and Coauthors, 2013: The Norwegian Earth System Model, NorESM1-M-Part 1: Description and basic evaluation of the physical climate. Geosci. Model Dev., 6, 687-720, https://doi.org/10.5194/gmd-6-687-2013.

Bi, D., and Coauthors, 2013: The ACCESS coupled model: Description, control climate and evaluation. Aust. Meteor. Oceanogr. J., 63, 41-64, https://doi.org/10.22499/2.6301.004.

Birch, C. E., M. J. Roberts, L. Garcia-Carreras, D. Ackerley, M. J. Reeder, A. P. Lock, and R. Schiemann, 2015: Sea-breeze dynamics and convection initiation: The influence of convective parameterization in weather and climate model biases. J. Climate, 28, 8093-8108, https://doi.org/10.1175/ JCLI-D-14-00850.1.

Bosveld, F. C., P. Baas, E. Van Meijgaard, E. I. de Bruijn, G. J. Steeneveld, and A. A. Holtslag, 2014a: The third GABLS intercomparison case for evaluation studies of boundary-layer models. Part A: Case selection and set-up. Bound.-Layer Meteor., 152, 133-156, https://doi.org/10.1007/s10546-014-9917-3.

, and Coauthors, 2014b: The third GABLS intercomparison case for evaluation studies of boundary-layer models. Part B: Results and process understanding. Bound.-Layer Meteor., 152, 157-187, https://doi.org/10.1007/s10546-014-9919-1.

Bretherton, C. S., and Coauthors, 2004: The EPIC 2001 stratocumulus study. Bull. Amer. Meteor. Soc., 85, 967-977, https:// doi.org/10.1175/BAMS-85-7-967.

Chen, X., B. Škerlak, M. W. Rotach, J. A. Añel, Z. Su, Y. Ma, and M. Li, 2016: Reasons for the extremely high-ranging planetary boundary layer over the western Tibetan Plateau in winter. J. Atmos. Sci., 73, 2021-2038, https://doi.org/10.1175/ JAS-D-15-0148.1.

Cheng, Y., V. M. Canuto, and A. M. Howard, 2002: An improved model for the turbulent PBL. J. Atmos. Sci., 59, 1550-1565, https://doi.org/10.1175/1520-0469(2002)059<1550: AIMFTT>2.0.CO;2.

Cohen, J. L., J. C. Furtado, M. Barlow, V. A. Alexeev, and J. E. Cherry, 2012: Asymmetric seasonal temperature trends. 
Geophys. Res. Lett., 39, L04705, https://doi.org/10.1029/ 2011 GL050582.

Cuxart, J., and Coauthors, 2006: Single-column model intercomparison for a stably stratified atmospheric boundary layer. Bound.-Layer Meteor., 118, 273-303, https://doi.org/10.1007/ s10546-005-3780-1.

Davy, R., and I. Esau, 2014: Global climate models' bias in surface temperature trends and variability. Environ. Res. Lett., 9, 114024, https://doi.org/10.1088/1748-9326/9/11/114024.

— , and - 2016: Differences in the efficacy of climate forcings explained by variations in atmospheric boundary layer depth. Nat. Commun., 7, 11690, https://doi.org/10.1038/ncomms11690.

,$- \ldots$, A. Chernokulsky, S. Outten, and S. Zilitinkevich, 2017: Diurnal asymmetry to the observed global warming. Int. J. Climatol., 37, 79-93, https://doi.org/10.1002/joc.4688.

Dee, D. P., and Coauthors, 2011: The ERA-Interim reanalysis: Configuration and performance of the data assimilation system. Quart. J. Roy. Meteor. Soc., 137, 553-597, https://doi.org/ 10.1002/qj.828.

Demory, M. E., P. L. Vidale, M. J. Roberts, P. Berrisford, J. Strachan, R. Schiemann, and M. S. Mizielinski, 2014: The role of horizontal resolution in simulating drivers of the global hydrological cycle. Climate Dyn., 42, 2201-2225, https:// doi.org/10.1007/s00382-013-1924-4.

de Souza Custodio, M., R. P. da Rocha, T. Ambrizzi, P. L. Vidale, and M. E. Demory, 2017: Impact of increased horizontal resolution in coupled and atmosphere-only models of the HadGEM1 family upon the climate patterns of South America. Climate Dyn., 48, 3341-3364, https://doi.org/10.1007/ s00382-016-3271-8.

Dufresne, J. L., and Coauthors, 2013: Climate change projections using the IPSL-CM5 Earth system model: From CMIP3 to CMIP5. Climate Dyn., 40, 2123-2165, https://doi.org/10.1007/ s00382-012-1636-1.

Dunne, J. P., and Coauthors, 2012: GFDL's ESM2 global coupled climate-carbon Earth system models. Part I: Physical formulation and baseline simulation characteristics. J. Climate, 25, 6646-6665, https://doi.org/10.1175/JCLI-D-11-00560.1.

Esau, I., and S. Zilitinkevich, 2010: On the role of the planetary boundary layer depth in the climate system. Adv. Sci. Res., $\mathbf{4}$, 63-69, https://doi.org/10.5194/asr-4-63-2010.

Garratt, J. R., 1993: Sensitivity of climate simulations to landsurface and atmospheric boundary-layer treatments-A review. J. Climate, 6, 419-448, https://doi.org/10.1175/ 1520-0442(1993)006<0419:SOCSTL > 2.0.CO;2.

Grachev, A. A., E. L Andreas, C. W. Fairall, P. S. Guest, and P. O. G. Persson, 2013: The critical Richardson number and limits of applicability of local similarity theory in the stable boundary layer. Bound.-Layer Meteor., 147, 51-82, https:// doi.org/10.1007/s10546-012-9771-0.

Griffies, S. M., and Coauthors, 2011: The GFDL CM3 coupled climate model: Characteristics of the ocean and sea ice simulations. J. Climate, 24, 3520-3544, https://doi.org/10.1175/ 2011JCLI3964.1.

Hannay, C., D. L. Williamson, J. J. Hack, J. T. Kiehl, J. G. Olson, S. A. Klein, C. S. Bretherton, and M. Köhler, 2009: Evaluation of forecasted southeast Pacific stratocumulus in the NCAR, GFDL, and ECMWF models. J. Climate, 22, 2871-2889, https://doi.org/10.1175/2008JCLI2479.1.

Hertwig, E., J. S. von Storch, D. Handorf, K. Dethloff, I. Fast, and T. Krismer, 2015: Effect of horizontal resolution on ECHAM6AMIP performance. Climate Dyn., 45, 185-211, https://doi.org/ 10.1007/s00382-014-2396-x.
Holtslag, B., 2006: Preface: GEWEX Atmospheric BoundaryLayer Study (GABLS) on stable boundary layers. Bound.Layer Meteor., 118, 243-246, https://doi.org/10.1007/ s10546-005-9008-6.

_ , and B. A. Boville, 1993: Local versus nonlocal boundarylayer diffusion in a global climate model. J. Climate, $\mathbf{6}$, 1825-1842, https://doi.org/10.1175/1520-0442(1993)006<1825: LVNBLD $>2.0 . \mathrm{CO} ; 2$.

- , and Coauthors, 2013: Stable atmospheric boundary layers and diurnal cycles: Challenges for weather and climate models. Bull. Amer. Meteor. Soc., 94, 1691-1706, https://doi.org/10.1175/ BAMS-D-11-00187.1.

Janssen, P. and J.-R. Bidlot, 2003: Part VII: ECMWF wave-model documentation. IFS Documentation Cycle CY23R4, ECMWF, 79 pp., https://www.ecmwf.int/sites/default/files/elibrary/2014/ 9207-part-vii-ecmwf-wave-model.pdf.

Johnson, S. J., and Coauthors, 2016: The resolution sensitivity of the South Asian monsoon and Indo-Pacific in a global 0.35 AGCM. Climate Dyn., 46, 807-831, https://doi.org/10.1007/ s00382-015-2614-1.

Jones, C. D., and Coauthors, 2011: The HadGEM2-ES implementation of CMIP5 centennial simulations. Geosci. Model Dev., 4, 543-570, https://doi.org/10.5194/gmd-4-543-2011.

Karlsson, J., and J. Teixeira, 2014: A simple model of the northeast Pacific stratocumulus to cumulus transition based on the climatological surface energy budget. J. Climate, 27, 4111-4121, https://doi.org/10.1175/JCLI-D-13-00534.1.

Klein, S. A., and D. L. Hartmann, 1993: The seasonal cycle of low stratiform clouds. J. Climate, 6, 1587-1606, https://doi.org/ 10.1175/1520-0442(1993)006<1587:TSCOLS>2.0.CO;2.

Lee, T. R., and S. F. J. De Wekker, 2016: Estimating daytime planetary boundary layer heights over a valley from rawinsonde observations at a nearby airport: An application to the Page Valley in Virginia, United States. J. Appl. Meteor. Climatol., 55, 791-809, https://doi.org/10.1175/ JAMC-D-15-0300.1.

— of regular rawinsonde measurements for elucidating key climatological and spatiotemporal patterns of afternoon boundary layer depths over the contiguous US. Adv. Meteor., 2017, 6841239, https://doi.org/10.1155/2017/ 6841239.

Li, L., and Coauthors, 2013: The Flexible Global OceanAtmosphere-Land System model, grid-point version 2: FGOALS-g2. Adv. Atmos. Sci., 30, 543-560, https://doi.org/ 10.1007/s00376-012-2140-6.

Lindvall, J., and G. Svensson, 2015: The diurnal temperature range in the CMIP5 models. Climate Dyn., 44, 405-421, https:// doi.org/10.1007/s00382-014-2144-2.

Liu, J., J. Huang, B. Chen, T. Zhou, H. Yan, H. Jin, Z. Huang, and B. Zhang, 2015: Comparisons of PBL heights derived from CALIPSO and ECMWF reanalysis data over China. J. Quant. Spectrosc. Radiat. Transfer, 153, 102-112, https://doi.org/ 10.1016/j.jqsrt.2014.10.011.

Liu, S., and X. Liang, 2010: Observed diurnal cycle climatology of planetary boundary layer height. J. Climate, 23, 5790-5809, https://doi.org/10.1175/2010JCLI3552.1.

Mahrt, L., 2014: Stably stratified atmospheric boundary layers. Annu. Rev. Fluid Mech., 46, 23-45, https://doi.org/10.1146/ annurev-fluid-010313-141354.

Mauritsen, T., and Coauthors, 2012: Tuning the climate of a global model. J. Adv. Model. Earth Syst., 4, M00A01, https://doi.org/ 10.1029/2012MS000154. 
McGrath-Spangler, E. L., and A. Molod, 2014: Comparison of GEOS-5 AGCM planetary boundary layer depths computed with various definitions. Atmos. Chem. Phys., 14, 6717-6727, https://doi.org/10.5194/acp-14-6717-2014.

Medeiros, B., A. Hall, and B. Stevens, 2005: What controls the mean depth of the PBL? J. Climate, 18, 3157-3172, https:// doi.org/10.1175/JCLI3417.1.

Meehl, G. A., and Coauthors, 2012: Climate system response to external forcings and climate change projections in CCSM4. J. Climate, 25, 3661-3683, https://doi.org/10.1175/ JCLI-D-11-00240.1.

Oke, T. R., 1976: The distinction between canopy and boundarylayer urban heat islands. Atmosphere, 14, 268-277, https:// doi.org/10.1080/00046973.1976.9648422.

_ 1995: The heat island of the urban boundary layer: Characteristics, causes and effects. Wind Climate in Cities, J. E. Cermak et al., Eds., Springer, 81-107.

Prodhomme, C., L. Batté, F. Massonnet, P. Davini, O. Bellprat, V. Guemas, and F. Doblas-Reyes, 2016: Benefits of increasing the model resolution for the seasonal forecast quality in EC-Earth. J. Climate, 29, 9141-9162, https://doi.org/10.1175/ JCLI-D-16-0117.1.

Quan, J., X. Tie, Q. Zhang, Q. Liu, X. Li, Y. Gao, and D. Zhao, 2014: Characteristics of heavy aerosol pollution during the 2012-2013 winter in Beijing, China. Atmos. Environ., 88, 83-89, https://doi.org/10.1016/j.atmosenv.2014.01.058.

Seidel, D. J., C. O. Ao, and K. Li, 2010: Estimating climatological planetary boundary layer heights from radiosonde observations: Comparison of methods and uncertainty analysis. J. Geophys. Res., 115, D16113, https://doi.org/10.1029/ 2009JD013680.

—, Y. Zhang, A. Beljaars, J.-C. Golaz, A. R. Jacobson, and B. Medeiros, 2012: Climatology of the planetary boundary layer over the continental United States and Europe. J. Geophys. Res., 117, D17106, https://doi.org/10.1029/2012JD018143.

Shaffrey, L. C., and Coauthors, 2009: U.K. HiGEM: The new U.K. High-Resolution Global Environment Model-Model description and basic evaluation. J. Climate, 22, 1861-1896, https://doi.org/10.1175/2008JCLI2508.1.

Stevens, B., 2002: Entrainment in stratocumulus-topped mixed layers. Quart. J. Roy. Meteor. Soc., 128, 2663-2690, https:// doi.org/10.1256/qj.01.202.

Svensson, G., and A. A. M. Holtslag, 2008, June. The second GABLS experiment-What did we learn? 18th Symp. on Boundary Layers and Turbulence, Stockholm, Sweden, Amer. Meteor. Soc., 8A.1, https://ams.confex.com/ams/18BLT/ webprogram/Paper140011.html. and J. Lindvall, 2015: Evaluation of near-surface variables and the vertical structure of the boundary layer in CMIP5 models. J. Climate, 28, 5233-5253, https://doi.org/10.1175/ JCLI-D-14-00596.1.

, and Coauthors, 2011: Evaluation of the diurnal cycle in the atmospheric boundary layer over land as represented by a variety of single-column models: The second GABLS experiment. Bound.-Layer Meteor., 140, 177-206, https://doi.org/ 10.1007/s10546-011-9611-7.

Voldoire, A., and Coauthors, 2013: The CNRM-CM5.1 global climate model: Description and basic evaluation. Climate Dyn., 40, 2091, https://doi.org/10.1007/s00382-011-1259-y.

Von Engeln, A., and J. Teixeira, 2013: A planetary boundary layer height climatology derived from ECMWF reanalysis data. J. Climate, 26, 6575-6590, https://doi.org/10.1175/ JCLI-D-12-00385.1.

Wang, F., X. Xin, Z. Wang, Y. Cheng, J. Zhang, and S. Yang, 2014: Evaluation of cloud vertical structure simulated by recent BCC_AGCM versions through comparison with CALIPSOGOCCP data. Adv. Atmos. Sci., 31, 721-733, https://doi.org/ 10.1007/s00376-013-3099-7.

Wang, X. Y., and K. C. Wang, 2016: Homogenized variability of radiosonde-derived atmospheric boundary layer height over the global land surface from 1973 to 2014. J. Climate, 29, 68936908, https://doi.org/10.1175/JCLI-D-15-0766.1.

Watanabe, M., and Coauthors, 2010: Improved climate simulation by MIROC5: Mean states, variability, and climate sensitivity. J. Climate, 23, 6312-6335, https://doi.org/10.1175/2010JCLI3679.1.

Watanabe, S., and Coauthors, 2011: MIROC-ESM 2010: Model description and basic results of CMIP5-20c3m experiments. Geosci. Model Dev., 4, 845-872, https://doi.org/10.5194/gmd-4-845-2011.

Wei, N., L. Zhou, and Y. Dai, 2017: Evaluation of simulated climatological diurnal temperature range in CMIP5 models from the perspective of planetary boundary layer turbulent mixing. Climate Dyn., 49, 1-22, https://doi.org/10.1007/s00382-016-3323-0.

Wu, T., and Coauthors, 2014: An overview of BCC climate system model development and application for climate change studies. Acta Meteor. Sin., 28, 34-56, https://doi.org/10.1007/ s13351-014-3041-7.

Yukimoto, S., and Coauthors, 2012: A new global climate model of the meteorological research institute: MRI-CGCM3. J. Meteor. Soc. Japan, 90A, 23-64, https://doi.org/10.2151/jmsj.2012-A02.

Zilitinkevich, S., and I. N. Esau, 2007: Similarity theory and calculation of turbulent fluxes at the surface for the stably stratified atmospheric boundary layer. Atmospheric Boundary Layers, A. Baklanov and B. Grisogono, Eds., Springer, 37-49, https://doi.org/10.1007/978-0-387-74321-9_4. 